\title{
A Comparison of Spectral Parameter Kappa from Small and Moderate Earthquakes Using Southern California ANZA Seismic Network Data
}

\author{
by Debi Kilb, Glenn Biasi, John Anderson, James Brune, Zhigang Peng, and Frank L. Vernon
}

\begin{abstract}
Kappa is a one-parameter estimator of the spectral amplitude decay with frequency of a seismogram. Low values $(\sim 5 \mathrm{~ms})$ indicate limited attenuation of highfrequency energy whereas higher values $(\sim 40 \mathrm{~ms})$ indicate high-frequency energy has been removed. Kappa is often assumed to be a site term and used in seismic designs. We address two key questions about kappa: (1) how to identify source, path, and site contributions to kappa; and (2) can kappa estimates from smaller earthquakes, and more readily accessible weak-motion recordings, be reasonably extrapolated to estimate kappa of larger earthquakes? The use of small earthquakes $\left(M_{\mathrm{L}}<1\right)$ presents many challenges and requires new approaches. We develop estimates of kappa for seismograms from 1137 small earthquakes recorded by the ANZA seismic network in southern California, and compare these to results from the stronger recorded shaking generated by $43 M_{\mathrm{L}}>3.5$ earthquakes inside the network. We find kappa from small earthquakes predicts the relative values of kappa for larger earthquakes (e.g., measurements at stations PFO and KNW are small compared with those at stations TRO and SND). For the SND and TRO data, however, kappa values from small earthquakes overpredict those from moderate and large earthquakes. Site effects are the most important contributor to kappa estimates, but the scatter within kappa measurements at a given station is likely caused by a significant contribution from near the source, perhaps related to near-source scattering. Because of this source-side variability, care is recommended in using individual small events as Green's functions to study source-time effects of moderate and large events.
\end{abstract}

\section{Introduction}

How seismic energy from an earthquake source attenuates as seismic waves travel from the source to the recording station has been studied for decades (e.g. Press, 1964; Anderson, 1986; Abercrombie, 1995; Aki and Richards, 2002; Anderson, 2007). Key in understanding this process is having access to large datasets rich in earthquakes from essentially the same location with similar magnitudes and comparable recordings. Given this, uncertainties in parameter measurements and potential causes for the deviations in the measurements can be established. Over the last decade, the density, footprint, and capability of seismic networks have greatly increased (e.g., Tikoff et al., 2006) allowing small earthquakes $\left(M_{\mathrm{L}}<1\right)$ to be routinely identified and cataloged. Because of these advancements, small quakes are now routinely used to infer the behavior of larger quakes in the same region, which may be particularly useful in regions where strong-motion data of even M 3.5 earthquakes are not available. In this work, we explore the appropriateness of these extrapolations using the parameter kappa, which is a single-parameter estimate of the decay of seismic spectral amplitudes with frequency (Anderson and Hough, 1984).
We quantify properties of earthquake spectra, and the associated uncertainties of these properties, using a dataset of 1180 earthquakes that locate within $40 \mathrm{~km}$ of the centroid of the ANZA Seismic Network in southern California (Fig. 1). Comparing kappa estimates from a suite of small earthquakes $\left(0.5<M_{\mathrm{L}}<1\right)$ with kappa estimates from larger earthquakes $\left(M_{\mathrm{L}}>3.5\right.$, including two $M_{\mathrm{L}} 5+$ events), we are able to evaluate how well each suite can predict the other. Specifically, our goals include: (1) assessing how reliably kappa measurements from small magnitude earthquakes $\left(0.5<M_{\mathrm{L}}<1.0\right)$ predict those from large magnitude earthquakes $\left(M_{\mathrm{L}}>3.5\right)$; (2) determining the influence of source and site characteristics on the shape of the seismic spectrum and the interplay between kappa and source, station, and path effects; and (3) quantifying uncertainties in our measurements.

\section{ANZA Seismic Network Data}

The ANZA seismic network (see the Data and Resources section) includes high-quality weak- and strong- 


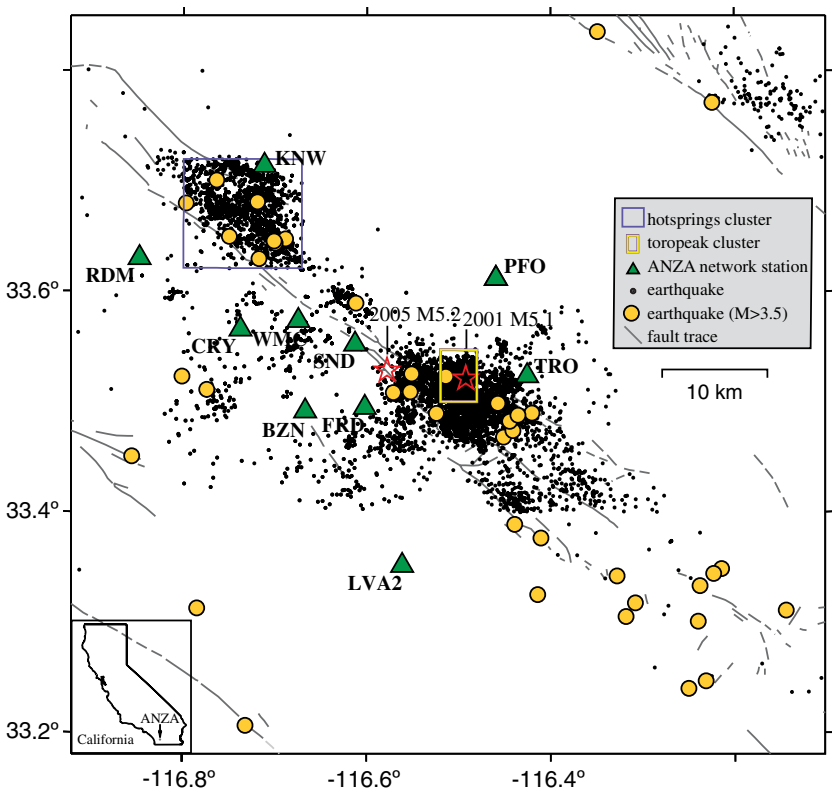

Figure 1. Study region in southern California. The inset shows the location with respect to the state of California. Large magnitude events $(M>3.5)$ are shown as circles, and the $2001 M_{\mathrm{L}} 5.1$ Anza (lat $=33.52$, lon $=-116.49$, depth $=15.4 \mathrm{~km}$ ) and the 2005 $M_{\mathrm{L}} 5.2$ Anza $($ lat $=33.53$, lon $=-116.58$, depth $=15.8 \mathrm{~km})$ mainshocks are shown as labeled stars. For small magnitude events (points) we focus on seismicity data from the Hot Springs cluster (upper box; encompassing the region $33.62<$ lat $<33.72$, $-116.80<$ lon $<-116.67$ and depth $<20 \mathrm{~km} ; 841$ earthquakes) and the Toro Peak cluster (lower box; encompassing the region $33.5<$ lat $<33.55, \quad-116.52<$ lon $<-116.48$ and depth $<$ $20 \mathrm{~km} ; 1073$ earthquakes). The ANZA network stations (triangles) are labeled. Stations MONP, YAQ, and SOL are outside the map area. The color version of this figure is available only in the electronic edition.

motion seismometers comprising an array spanning the San Jacinto Fault Zone (SJFZ) in southern California (see Fig. 1) (Berger et al., 1984; Vernon, 1989). This network is situated in a stable granitic terrain within a desert climate, and the tectonic environment near the ANZA network tends toward transpression (e.g., Sanders and Kanamori, 1984). This network has been operational over the past $\sim 28$ years (see Tables 1 and 2 for information about ANZA station locations and site conditions) and is currently capable of recording local earthquakes at or above magnitude $\sim 0.5$ on scale and above the noise level. The ANZA catalog contains $~ 9200$ earthquakes within $40 \mathrm{~km}$ of the network centroid (33.52 $\mathrm{N}, 116.50 \mathrm{~W})$ that were recorded with high sample rates ( $\geq 100 \mathrm{sps}$ ) by at least four stations. These near-field data have a completeness level of $M \sim 1.6$ over all years of recording, and here we use data from 1985 to 2006.

The ANZA earthquake catalog contains two clusters of seismicity useful for exploring the near-source and near-site contributions to kappa (Hot Springs and Toro Peak clusters). Of the two clusters, the Hot Springs cluster of 841 small earthquakes (upper left box in Fig. 1) has the larger footprint, spanning $\sim 10 \mathrm{~km}$ by $10 \mathrm{~km}$, and the rate of seismicity within this cluster is relatively constant. The Toro Peak cluster (lower right box in Fig. 1) is constrained to a smaller mapped area of approximately $5 \mathrm{~km}$ by $5 \mathrm{~km}$ and a depth span of $\sim 10 \mathrm{~km}$. The average 3D distance between earthquakes in this cluster is $2.6 \mathrm{~km}$. These data include 296 earthquakes, of which 181 occurred within the 2-week period following the 31 October $2001 M_{\mathrm{L}} 5.1$ Anza earthquake and are likely aftershocks of that event.

By examining small earthquakes in these limited geographic areas, the differences in path effects among earthquakes are reduced, allowing us to more confidently distinguish site and source-side contributions to kappa. We compare the kappa estimates from these small earthquakes with those from a set of 41 earthquakes over magnitude 3.5 in our study region, and to two $M_{\mathrm{L}}>5$ earthquakes, which produced the strongest recorded ground motions. We require all data to have an analyst picked $S$-wave arrival at a minimum of four stations, a well-defined network magnitude, and a sample rate of 100 sps or greater.

Table 1

Locations and Duration of Operation of Select ANZA Seismic Network Stations Used in This Study

\begin{tabular}{ccccc}
\hline Station Name & Latitude $\left(^{\circ}\right)$ & Longitude $\left({ }^{\circ}\right)$ & $\begin{array}{c}\text { Elevation above } \\
\text { Sea Level }(\mathrm{km})\end{array}$ & $\begin{array}{c}\text { Station on Date } \\
(\mathrm{mm} / \mathrm{dd} / \mathrm{yyyy})\end{array}$ \\
\hline BZN & 33.4915 & -116.6670 & 1.301 & $01 / 20 / 1983$ \\
CRY & 33.5654 & -116.7373 & 1.128 & $11 / 01 / 1982$ \\
FRD & 33.4947 & -116.6022 & 1.164 & $11 / 01 / 1982$ \\
KNW & 33.7141 & -116.7119 & 1.507 & $11 / 01 / 1982$ \\
LVA2 & 33.3516 & -116.5615 & 1.435 & $04 / 18 / 1993$ \\
MONP & 32.8927 & -116.4225 & 1.920 & $02 / 02 / 1998$ \\
PFO & 33.6117 & -116.4594 & 1.259 & $11 / 01 / 1982$ \\
RDM & 33.6300 & -116.8478 & 1.365 & $11 / 01 / 1982$ \\
SND & 33.5519 & -116.6129 & 1.358 & $11 / 01 / 1983$ \\
SOL & 32.8410 & -117.2480 & 0.245 & $02 / 09 / 1996$ \\
TRO & 33.5234 & -116.4257 & 2.628 & $11 / 01 / 1982$ \\
WMC & 33.5736 & -116.6747 & 1.271 & $09 / 16 / 1983$ \\
\hline
\end{tabular}


Table 2

Site Descriptions* for Select ANZA Seismic Network Stations in This Study, Ordered by Station Name ${ }^{\dagger}$

\begin{tabular}{|c|c|}
\hline Station Name & Surface Rocks \\
\hline BZN & $\begin{array}{l}\text { Decomposed tonalite of the Cahuilla Mtn. pluton that extends many kilometers west of the station. The nearest sediment contact is } \sim 50 \mathrm{~m} \\
\text { east of the station. The sediments get progressively thicker toward the east until reaching a depth of } 150-200 \mathrm{~m} \text { several } \mathrm{km} \text { away in } \\
\text { Terwilliger Valley and overlie the Cahuilla Valley pluton. The nearest metamorphic contact is } 2 \mathrm{~km} \text { to the south. The site is near the top } \\
\text { of a gentle eastward dipping slope that has minimal relief. }\end{array}$ \\
\hline CRY & $\begin{array}{l}\text { Small outcrop of tonalite basement at the end of a small alluvial valley, part of the Cahuilla Valley pluton. The nearest boundary of the } \\
\text { pluton is } \sim 1 \mathrm{~km} \text { to the northwest. Shallow local alluvial sediments }<20 \mathrm{~m} \text { thick surround the station at a minimum distance of } 30 \mathrm{~m} \\
\text { away. The station is on a small knoll } \sim 10 \mathrm{~m} \text { high surrounded by granitic boulders. The local terrain is quite flat. }\end{array}$ \\
\hline FRD & $\begin{array}{l}\text { Tonalite of the Cahuilla Valley pluton. The nearest sediments are alluvium } \sim 50 \mathrm{~m} \text { to the north, which reach a depth of } \sim 200 \mathrm{~m} \text { about } 2 \mathrm{~km} \\
\text { northwest of the station. The nearest metamorphic outcrops are } 3 \mathrm{~km} \text { south of the station. The station is located near the edge of a } \\
\text { shallow alluvial valley and on the flank of a low east ridge trending along the southern side of Terwilliger Valley. }\end{array}$ \\
\hline KNW & $\begin{array}{l}\text { Tonalitic basement located in the San Jacinto Mountain intrusive complex. The weathering layer is about } 20 \mathrm{~m} \text { thick. The nearest sed- } \\
\text { iments are } \sim 1 \mathrm{~km} \text { to the southwest. There are no metamorphic outcrops within } \sim 5 \mathrm{~km} \text {. The station is located on the crest of a small } \\
\text { descending ridge oriented north-northwest. The local topography consists of small low amplitude ridges and valleys overlying a gen- } \\
\text { eral slope from the San Jacinto Mountains on the north to the saddle at Mountain Center } \sim 2 \mathrm{~km} \text { to the south. }\end{array}$ \\
\hline LVA2 & $\begin{array}{l}\text { Granodiorite of the Collins Valley pluton. The nearest sediment contact is from the small, alluvium-filled Lost Valley } 500 \mathrm{~m} \text { west of the } \\
\text { station. The site is on a low rise on the east side of Lost Valley, which is essentially flat. The valley is surrounded by ridges several } \\
\text { hundred meters in height around Lost Valley. Hot Springs Peak is } 3.5 \mathrm{~km} \text { south and } 500 \mathrm{~m} \text { above the LVA2 station. Six kilometers north } \\
\text { of LVA2 is the 600-m-deep Coyote Canyon. The original LVA site was moved here due to anomalous site effects with amplified low- } \\
\text { frequency signals. }\end{array}$ \\
\hline PFO & $\begin{array}{l}\text { Decomposed quartz diorite-granodiorite, part of the Haystack Pluton. The depth of the weathering layer is } \sim 20 \mathrm{~m} \text {. There are no nearby } \\
\text { sediments. The nearest metamorphic outcrops are } \sim 3 \mathrm{~km} \text { to the west and south. The site is located on Pinyon Flat. The topography is } \\
\text { flat for several } \mathrm{km} \text { in all directions, with a } \sim 2.5^{\circ} \text { slope to the south. Pinyon Flat is bounded by Asbestos Mtn. (N), Deep Canyon (E), } \\
\text { Santa Rosa Mtn. (S), and Palm Canyon (W). }\end{array}$ \\
\hline $\mathrm{RDM}$ & $\begin{array}{l}\text { The metamorphic rock primarily consists of layered gneiss. The station is located several meters from the metamorphic-tonalite contact. } \\
\text { The surface boundary of the pluton appears to be } 1 \mathrm{~km} \text { to the northeast. The nearest sediments are }>1 \mathrm{~km} \text { distant. The station is located } \\
\text { on top of a small mountain that rises } 400 \mathrm{~m} \text { above the surrounding land. Red Mtn. is part of northwest trending ridge which extends } \\
10 \mathrm{~km} \text { from the } 1735-\mathrm{m} \text { Cahuilla Mtn. }\end{array}$ \\
\hline SND & $\begin{array}{l}\text { Decomposed tonalite of the Cahuilla Valley pluton. The nearest sediments are in a small shallow alluvial valley } \sim 50 \mathrm{~m} \text { away. The nearest } \\
\text { metamorphic outcrops are } \sim 100 \mathrm{~m} \text { away. This station is located in the trifurcation area of the San Jacinto fault zone and is } \sim 100 \mathrm{~m} \text { from } \\
\text { the surface trace of the Clark fault. The station is located on the north end of Table Mtn. The station overlooks the slope down to } \\
\text { Hamilton Creek and Burnt Valley, which are } 30 \mathrm{~m} \text { lower than the station. }\end{array}$ \\
\hline TRO & $\begin{array}{l}\text { Quartz diorite-granodiorite, located in the middle of the Santa Rosa Pluton. The nearest boundary of the pluton is }>5 \mathrm{~km} \text { away. There are } \\
\text { no nearby sediments. The nearest metamorphic outcrops are } \sim 1 \mathrm{~km} \text { distant. The station is at the top of a } 2657 \mathrm{~m} \text { peak that is part of an } \\
\text { elongated ridge with a northwest major axis. The elevation drops to } 1700 \mathrm{~m} \sim 5 \mathrm{~km} \text { north and } \sim 5 \mathrm{~km} \text { south of the station. }\end{array}$ \\
\hline WMC & $\begin{array}{l}\text { Alluvium and sediment that are about } 60 \mathrm{~m} \text { thick. The site is } \sim 30 \mathrm{~m} \text { north of a metamorphic outcrop. There are no plutonic outcrops } \\
\text { within } 2 \mathrm{~km} \text {. The site is } 3 \mathrm{~km} \text { from the surface trace of the Clark fault. The topography is gently sloping to the south with no relief. The } \\
\text { nearest topographic feature is Thomas Mtn. } 4 \mathrm{~km} \text { to the north. }\end{array}$ \\
\hline
\end{tabular}

*Information primarily from Vernon, 1989 and Anderson, 1991.

'Ordering the stations from those on hard rock to those on non-hard rock yields: KNW, LVA2, FRD, RDM, TRO, PFO, CRY, BZN, WMC, and SND.

\section{Definitions of Kappa: AH-Kappa, Acceleration- Kappa, Displacement-Kappa and Fixed-Kappa}

The parameter kappa describes the asymptotic highfrequency slope of the spectra of a seismogram. Low values of kappa correspond to seismograms with a lot of highfrequency energy, whereas high values of kappa correspond to seismograms with a minimal amount of high-frequency energy. Typically, the lower the kappa value the higher the expected ground motion (Mena et al., 2010). There are several ways to measure kappa (Table 3, Fig. 2). In the original definition given by Anderson and Hough (1984), kappa is estimated from the linear range of the acceleration spectral amplitude decay where it is above a noise floor. This approach assumes the corner frequency is far enough below the measurement window that the effect of corner-frequency rolloff can be neglected. Anderson and Humphrey (1991) extended the kappa estimation method to smaller magnitude earthquakes by interpreting kappa as the slope of the residual after subtracting a known spectral shape such as that predicted by the Brune (1970) omega-squared model (Fig. 2a).

For strong-motion engineering applications a problem arises in estimating kappa if the available seismicity is limited to earthquakes below $M_{\mathrm{L}} \sim 3.5$. In this magnitude range separating corner-frequency effects from kappa effects on the spectral shape is difficult (Hanks, 1982; Anderson and Humphrey, 1991). To get around this problem, an alternate kappa estimation method for small earthquakes was developed at the University of Nevada at Reno (Biasi and Smith, 2001) using the low-frequency asymptote of the displacement spectra (Fig. 2c). This method, most applicable for $M_{\mathrm{L}}<1.0$ earthquakes, relies on the assumption that stress drops for the smallest earthquakes are similar to those of larger earthquakes (Abercrombie, 1995; Shaw, 2009), and, as a result, have corner frequencies that are high relative to a frequency 
Table 3

Methods of Measuring Kappa, the Asymptotic High-Frequency Slope of the Spectra of a Seismogram

\begin{tabular}{|c|c|c|}
\hline Method & Description & Reference \\
\hline Original kappa & $\begin{array}{l}\text { Linear, least-squares fit to the acceleration spectrum, } f_{N}>f>f_{E} \text {, where } f_{E} \text { is slightly above the } \\
\text { corner frequency and } f_{N} \text { is the noise floor. Original kappa is primarily used for larger earthquakes } \\
\text { (e.g., } M \geq 5.0 \text { ). }\end{array}$ & $\begin{array}{l}\text { Anderson and Hough } \\
\text { (1984) }\end{array}$ \\
\hline AH-kappa & $\begin{array}{l}\text { Attempt to extend measurements to include earthquakes where the corner frequency affects kappa. } \\
\text { Assume the spectral shape in Equation 1, and interpret the slope of the difference as kappa. } \\
\text { Numerically one solves for } M_{0}, f_{0} \text {, and the kappa that minimizes the RMS misfit. }\end{array}$ & $\begin{array}{l}\text { Anderson and } \\
\text { Humphrey (1991) }\end{array}$ \\
\hline Displacement-kappa & $\begin{array}{l}\text { Assume the low-frequency displacement spectrum is flat below the corner frequency } f_{0} \text {, and that any } \\
\text { slope is due to kappa. Measure the slope of the displacement spectrum for } f \ll f 0 \text {. For small } \\
\text { enough earthquakes the frequency range can match that used in the original kappa method and be } \\
\text { applied to larger earthquakes. }\end{array}$ & $\begin{array}{l}\text { Biasi and Smith } \\
\quad(2001)\end{array}$ \\
\hline Acceleration-kappa & $\begin{array}{l}\text { Measure the slope of the acceleration spectrum for frequencies well above } f_{0} \text {. This method is the same } \\
\text { as the original kappa method, except it can be applied to smaller magnitude earthquakes } \\
(M \sim 3.5-5) \text { and typically uses data in the frequency band } 5-25 \mathrm{~Hz} \text {. }\end{array}$ & $\begin{array}{l}\text { Biasi and Smith } \\
\quad \text { (2001) }\end{array}$ \\
\hline Fixed-kappa & $\begin{array}{l}\text { Assume a fixed stress drop, and then use } M_{0} \text { to fix } f_{0} \text { in Equation } 1 \text {. This method may be used when } \\
\text { kappa and } f_{0} \text { trade off and } f_{0} \text { estimates from fitting are considered uncertain or suspect (see } \\
\text { equations } 4 \text { and 5). }\end{array}$ & This study \\
\hline
\end{tabular}

window in which kappa may be estimated. Under these conditions, the slope of the displacement spectrum in the measurement window is proportional to kappa. We can use an analogous computation to estimate kappa from the asymptotically flat portion of acceleration spectra above the corner frequency (Fig. 2b). This estimate, applicable to $M>3.5$ earthquakes, is effectively the estimate of Anderson and Hough (1984).

To explore potential corner-frequency effects, we also estimate kappa using a fixed stress drop (e.g., Abercrombie, 1995). Generally, the moment of small earthquakes is reasonably constrained by the spectrum, so fixing the stress drop will constrain the corner frequency of an event allowing a hypothetical assessment of kappa to be calculated. For consistency with a companion study that uses data from southern Nevada (Biasi and Anderson, 2007), we use 4.7 MPa for our constrained stress-drop calculations.

To differentiate between the different kappa measurements we use the terms displacement-kappa, accelerationkappa, AH-kappa, and fixed-kappa to refer to kappa measured from the low-frequency slope of the displacement spectra, the high-frequency slope of the acceleration spectra, the residual slope to an omega-squared spectrum, and kappa determined assuming a fixed stress-drop value, respectively
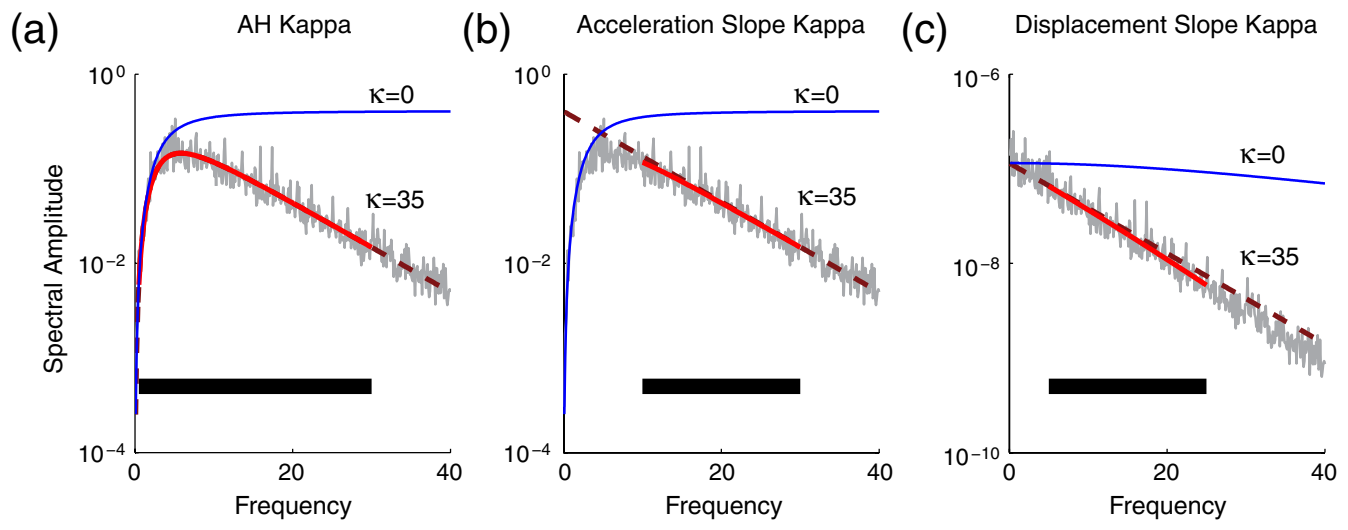

Figure 2. Cartoon spectra depicting different measurements of kappa. Each cartoon includes a reference $\kappa=0$ line (labeled thin line), the sample data for $\kappa=35 \mathrm{~ms}$ (light line), the measurement window length (thick bar), the spectral fit within the measurement window (red line), and the spectra of the model (dashed line). (a) AH-kappa derived from the residual slope to an omega-squared spectrum. This method is appropriate for small to moderate earthquakes $\left(M_{\mathrm{L}} \gtrsim 3.5\right)$ where the corner frequency is within the measurement window. (b) Accelerationslope kappa derived from acceleration spectra. This kappa estimate assumes that any slope in the spectra is caused by kappa (e.g., Anderson and Hough, 1984) and requires the corner frequency to be sufficiently smaller than the lower bound of the measurement window. This approximation is suitable for the data of most earthquakes of $M_{\mathrm{L}}>3.5$. (c) Displacement-slope kappa derived from the low-frequency asymptote of the displacement spectra. This method is appropriate for small earthquake data $\left(M_{\mathrm{L}}<1\right)$ and assumes the low-frequency displacement spectrum is flat below the corner frequency. The difference in slope between the model and fit lines results from an overestimate of kappa that is a consequence of the synthetic data having a corner frequency of $50 \mathrm{~Hz}$ whereas the model assumes the corner frequency is infinite. The color version of this figure is available only in the electronic edition. 
(Anderson and Hough, 1984; Anderson and Humphries, 1991; Biasi and Smith, 2001). AH-kappa measurements are more appropriate for moderate magnitude earthquakes $\left(M_{\mathrm{L}}>3.5\right)$ when the corner frequency is relatively low, and displacement-kappa measurements are more appropriate for small magnitude earthquakes $\left(M_{\mathrm{L}}<1.0\right)$ that have higher corner frequencies.

We emphasize that each of our kappa estimates are derived relative to an assumed model spectral shape. From source theory we have confidence that the low-frequency displacement-spectrum should be flat. This is in contrast to our lower confidence in the high-frequency fall-off rate of the acceleration spectra. In this study, any source-side variability in the rate of the high-frequency fall-off of the acceleration spectra is mapped into variability in the kappa parameter (both AH-kappa and acceleration-kappa). By quantifying deviations in kappa values for suites of similar earthquakes, we can gain a more complete understanding of what causes these deviations (i.e., from source, path, and site influences, or some combination of these factors).

Figure 3 shows examples of seismograms and spectra for low and high values of AH-kappa. This example uses data from an earthquake in the Toro Peak cluster of seismicity (lower rectangle in Fig. 1). Qualitatively examining the seismograms recorded at stations KNW and SND, it is clear that the strong high-frequency energy in the KNW recording is absent in the SND recording (Fig. 3a,b). The spectra of these recordings confirm these observations (Fig. 3c,d) with AH-kappa measurements of $6.6 \mathrm{~ms}$ for the $\mathrm{KNW}$ data and $49 \mathrm{~ms}$ for the SND recording. Importantly, this example

(a)

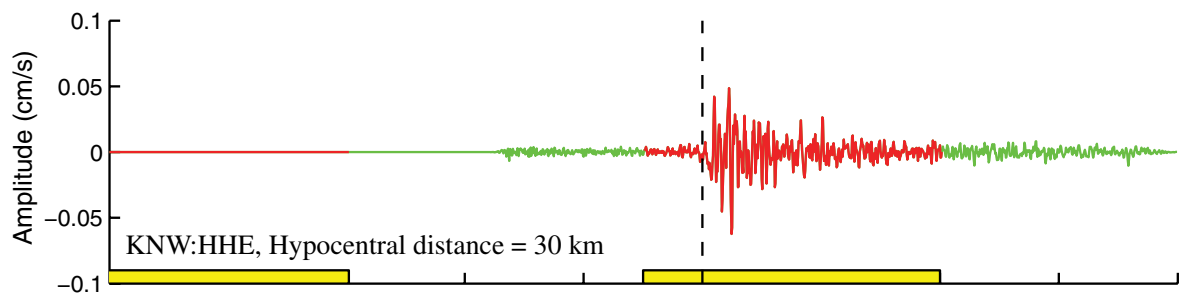

(b)

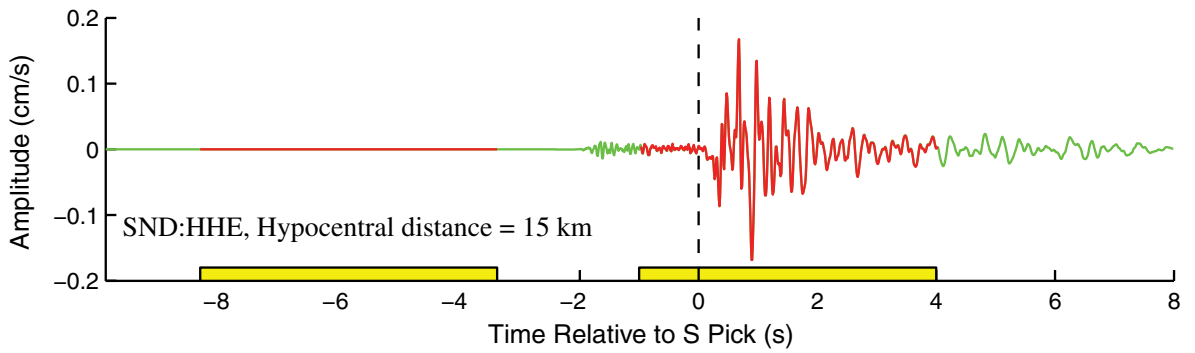

(c)

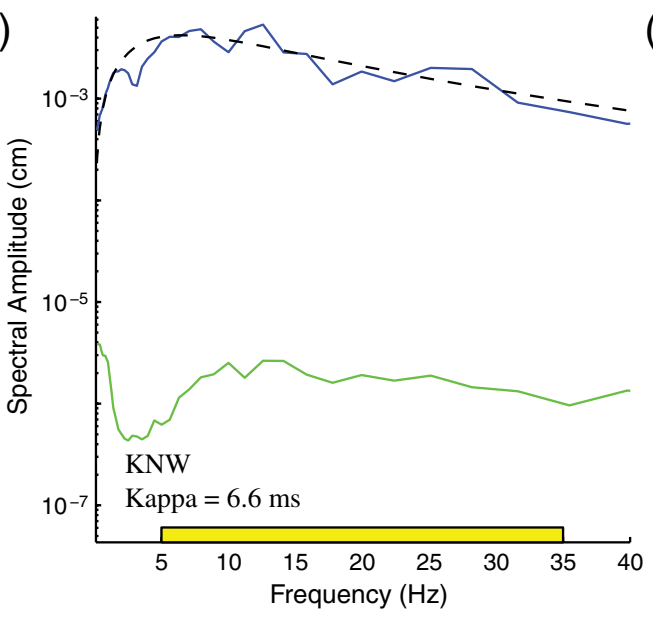

(d)

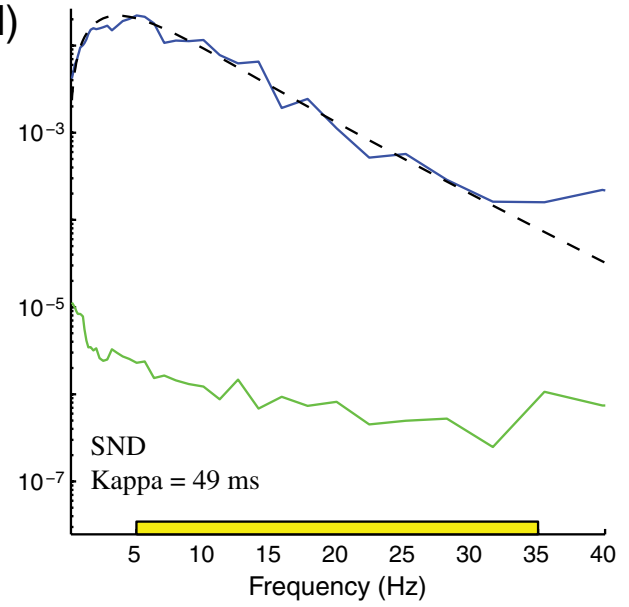

Figure 3. Analysis of a magnitude 3.6 earthquake on 07 February 1997 at 06:59:49 GMT that occurred in the Toro Peak cluster of seismicity (lat $=33.51$, lon $=-116.55$ ) at a depth of $12.53 \mathrm{~km}$. (a) Seismogram recorded at ANZA station KNW (located on hard rock; back azimuth, $147^{\circ}$; hypocentral distance, $30 \mathrm{~km}$; HHE component). Elongated rectangles identify the time windows of the noise window (left) and $S$-wave signal (right). (b) As in (a), for a seismogram recorded at ANZA station SND (located within the San Jacinto Fault Zone; back azimuth, $131^{\circ}$; hypocentral distance, $15 \mathrm{~km}$; HHE component) (c) Velocity spectra (dark solid line) and model fit (dashed line) for station KNW and noise spectra (light solid line). (d) As in (c), but for the data recorded at station SND. Note the enriched high-frequency energy at station $\mathrm{KNW}(\mathrm{AH}-\mathrm{kappa}=6.6 \mathrm{~ms})$, in comparison with that of station SND (AH-kappa $=49 \mathrm{~ms})$. The color version of this figure is available only in the electronic edition. 
shows a greater abundance of high-frequency energy at the more distant KNW station, which is counter to what is expected.

\section{Data Processing: Automated Determination of Corner Frequency, Kappa, Seismic Moment, and Stress Drop}

For each seismogram in our dataset, we compute the seismic spectra and then establish a best-fit model spectrum to the data. In our model, the unknowns we solve for include seismic moment $\left(M_{0}\right)$, corner frequency $\left(f_{0}\right)$, and kappa $(\kappa)$. Mathematically, we start with the seismic spectrum equation

$$
\begin{aligned}
& M(f, r) \\
& \quad=M_{0}\left(\frac{\Phi}{4 \pi \rho \beta^{3} r}\right)\left[(2 \pi f)^{\gamma}\right]\left[1+\left(\frac{f}{f_{0}}\right)^{\alpha}\right]^{-1} \exp (-\pi \kappa f),
\end{aligned}
$$

where $\gamma$ represents the data type, with $\gamma=0,1$, or 2 for displacement, velocity, or acceleration spectra, respectively. Here, $\Phi$ is the average radiation pattern $(0.85), \beta$ is the shear wave velocity at the source $(3.5 \mathrm{~km} / \mathrm{s}), r$ is the hypocentral distance $(\mathrm{km}), f$ is frequency in the spectrum, and $\alpha$ controls the rolloff of the spectrum above the corner frequency. The $1 / r$ term in the first bracket represents geometric spreading of body waves (Aki and Richards, 2002). We assume that $\alpha=2$, corresponding to the Brune $(1970,1971)$ spectral model. For $f \gg f_{0}$, kappa controls the spectral slope and can be measured with the definition used by Anderson and Hough (1984).

Taking the natural logarithm of both sides of equation (1), and using a least-squares fit to a discretized version of the spectrum, we estimate model parameters from

$$
\begin{aligned}
\ln \left[M\left(f_{i}, r\right)\right]= & \ln \left(M_{0}\right)+\ln \left(A_{0}\right)-\pi \kappa f_{i} \\
& +\ln \left\{\left(2 \pi f_{i}\right)^{\gamma}\left[1+\left(\frac{f_{i}}{f_{0}}\right)^{2}\right]^{-1}\right\},
\end{aligned}
$$

where $A_{0}$ represents the elements in the first brackets of equation (1). If the corner frequency $f_{0}$ is known (or assumed), equation (2) becomes linear in $M_{0}$ and $\kappa$. The resulting squared error of the fit is

$$
E^{2}\left(f_{0}\right)=\frac{1}{\mathrm{NF}} \sum_{i=1}^{\mathrm{NF}}\left\{\ln \left[A\left(f_{i}\right)\right]-\ln \left[M\left(f_{i}\right)\right]\right\}^{2},
$$

where $A(f)$ is the $S$-wave spectrum from the data and NF is the number of frequency bins in the spectrum. The Anderson and Humphrey (1991) method involves calculating $E^{2}$ for a wide range of trial $f_{0}$ values and assigning $\kappa, f_{0}$, and $M_{0}$ to values that minimize the misfit. After establishing $M_{0}$, we can compute stress drop by assuming a circular fault of radius $R$ (Eshelby, 1957; Brune, 1970, 1971):

$$
\Delta \sigma=\left(\frac{7 M_{0}}{16 R^{3}}\right)
$$

We approximate $R$ from (Brune, 1970, 1971; Beresnev, 2001)

$$
R=\left(\frac{2.34 \cdot \beta}{2 \cdot \pi \cdot f_{0}}\right) .
$$

To assure a minimum in the misfit function can be identified, if it exists, it is important to explore a wide range of cornerfrequency and kappa values. If no clear minimum is found, kappa is trading off with corner frequency and neither is uniquely resolved. Consequently, there can be a wide range of acceptable corner frequencies and the confidence bounds (i. e., $75 \%$ or $95 \%$ confidence) of kappa and corner-frequency ranges are not independent. Because of these issues we can gain some insight by computing kappa after first assuming a fixed stress-drop value.

For a displacement spectrum $\gamma=0$ and equation (1) becomes

$$
M_{d}(f, r)=\left(\frac{\Phi M_{0}}{4 \pi \rho \beta^{3} r}\right)\left[1+\left(\frac{f}{f_{0}}\right)^{\alpha}\right]^{-1} \operatorname{ep}(-\pi \kappa f) .
$$

Rearranging the terms, equation (6) can be rewritten as

$$
\begin{aligned}
\ln \left[M_{d}(f, r)\right]= & \ln \left(M_{0}\right)+\ln \left(\frac{\Phi}{4 \pi \rho \beta^{3} r}\right)-\pi \kappa f \\
& -\ln \left[1+\left(\frac{f}{f_{0}}\right)^{\alpha}\right]
\end{aligned}
$$

For small earthquakes, when the corner frequency $f_{0}$ is sufficiently high compared to the upper frequency of the displacement-kappa estimation window, the last term in equation (7) can be neglected and the least-square fit equation simplifies to

$$
\ln \left[M_{d}(f)\right]=\ln \left(M_{0}\right)+\ln \left(A_{0}\right)-\pi \kappa f .
$$

We use equation (8) to compute displacement-slope kappa. Equation (8) applies as long as $f_{0}$ does not scale with earthquake magnitude (i.e., smaller $f_{0}$ for smaller earthquakes), which should be the case if stress drops for small earthquakes are similar to those for larger earthquakes (Abercrombie, 1995; Shearer et al., 2006; Shaw, 2009). We also use equation (8) to compute acceleration-slope kappa from acceleration spectra of larger earthquakes $(M>3.5)$.

For each seismogram we determine the signal-to-noise ratio (SNR) and assess the quality of fit between the seismogram and our model. We use the signal just prior to the $P$-wave arrival to estimate the noise spectrum (Fig. 3). For the range of frequencies used to fit kappa, moment, and corner frequency (e.g., $0.5<f_{i}<35, \quad f_{i+1}=f_{i}+\Delta f$, and $\Delta f=0.01 \mathrm{~Hz}$ ) we compute the percentage of frequencies 
that are above an SNR threshold value (SNRpct). For our tests we require the SNR be above 5 for $75 \%$ of the frequency fitting windows, which we denote as SNRpct $>0.75$. In practice the SNR comes into play only for the smallest earthquakes.

We use the software suite kappaAH that we wrote for use with the MATLAB software and the Antelope Real Time System (ARTS) database extensions to automatically process the data (see the Data and Resources section). In this work, we use a 5-s waveform window beginning $1 \mathrm{~s}$ before the $S$-wave arrival time pick. We apply this fixed length 5-s window to all data to emphasize direct $S$-wave energy in the spectral estimates. For each seismogram we use a multitaper method to compute the seismic spectrum (Vernon, 1989). Our automated program also checks that the seismograms we examine do not overprint with previous or future seismograms that occur very close together in space and time, which would result in distortion of both waveforms. We test a range of trial corner frequencies and identify the one that minimizes the squared error fit of the data spectrum to a model spectrum. When multiple stations record data from the same earthquake we catalog the parameter values spectrum by spectrum (i.e., we do not require these values to be consistent across all stations). This process allows us to assess both the variability in values across stations for a given earthquake and also the range of values from a specific station for a suite of earthquakes. For each trial corner frequency, we solve for seismic moment and kappa, and in turn stress drop. Estimates of confidence ranges (75\% and $95 \%$ ) are computed for $\mathrm{AH}-$ kappa, displacement-kappa, acceleration-kappa, fixed-kappa and corner frequency. Displacement-kappa is computed for small magnitude earthquakes and AH-kappa for larger earthquakes $\left(M_{\mathrm{L}}>3.5\right)$. We also compute fixed-kappa values for all data and acceleration-kappa for the earthquakes with $M_{\mathrm{L}}>3.5$.

\section{Sample Output from the KappaAH Software Suite}

For each seismogram we process, we automatically generate summary figures, which include the original time series, the frequency spectra of the data (original signal, instrument corrected, best fitting model, and noise), and the SNR. Most features are configurable by the user, including the length and starting point of the time series, the spectral estimation method, prefiltering, the spectral range to fit, restrictions on SNR for quality estimation, and display in log or linear frequency. Instrument correction is also selectable. All parameters are configured in advance and applied to every seismogram in a batch calculation. The parameters can be easily changed and the batch calculation rerun to test parameter sensitivity.

From the summary figures one can determine if there is a strong minimum in the trade off among parameters near the trial corner frequency that best fits the seismic spectrum (Fig. 4). These graphical views provide a quick quality check of the data. Although not shown in Figure 4, a text box including the final parameter values and their uncertainties is listed at the bottom of each summary figure, along with the input values used in the computations.

\section{Results}

Small Earthquakes: Site, Distance, and Near-Source Effects on Displacement-Kappa Measurements

It is well known that attenuation removes high frequencies more effectively than low frequencies (Aki and Richards, 2002). Therefore, if there is a significant path attenuation contribution to kappa estimates, kappa should be higher for longer source-station separations. To test this hypothesis we first use small earthquakes $\left(0.5<M_{\mathrm{L}}<1.0\right)$ in the Hot Springs cluster of seismicity, restricting our measurements to horizontal component seismograms with SNRpct $>0.75$ recorded at stations $\mathrm{KNW}, \mathrm{PFO}, \mathrm{SND}$, and TRO. The source-station distances for these data range from $\sim 15 \mathrm{~km}$ (KNW) to $\sim 35 \mathrm{~km}$ (TRO), and the site conditions at these stations differ substantially (Table 2).

Figure 5a,b shows that the displacement-kappa results separate into distinct fields according to the recording stations. Seismograms recorded at station PFO generally have a substantial ringing that persists throughout the duration of the wave train, which results in a relatively long and high amplitude $P$-wave coda (Vernon et al., 1991). In contrast, the seismograms recorded at station $\mathrm{KNW}$ have a prevalence of high-frequency energy and relatively short coda duration. Distinctly different from the PFO and KNW data, recordings at stations SND and TRO tend to have minimal highfrequency energy. From these qualitative observations we expect displacement-kappa values at stations SND and TRO to be relatively high and displacement-kappa values at stations KNW and PFO to be relatively low. Indeed, quantitative tests confirm these estimates (Table 4, Fig. 5a,b). Similar results are found when we analyze small magnitude earthquakes in the Toro Peak cluster of seismicity (Fig. 5c,d) with seismograms recorded at stations $\mathrm{KNW}$ and $\mathrm{PFO}$ having the lowest values of displacement-kappa $(<25 \mathrm{~ms})$, significantly less than the displacement-kappa computed with the data from stations SND and TRO (>50 ms). These clear 25-55 ms differences are seen for both the Toro Peak cluster and the Hot Springs cluster, which have different sourcereceiver distances (see Fig. 5a,c and Table 4). The similarity of the mean displacement-kappa estimates for both clusters of seismicity suggests that the most important factor in displacement-kappa estimates is the site contribution (Table 4), which is consistent with the findings of past studies (e.g., Hough et al., 1988).

To verify that mean displacement-kappa estimates best correlate with site conditions, we systematically rule out other factors. We do not expect that large differences in mean kappa estimates are related to magnitude variations because the range of magnitudes is very narrow $\left(0.5<M_{\mathrm{L}}<1.0\right)$. We can also rule out distance as being the primary cause because while displacement-kappa appears to increase with 

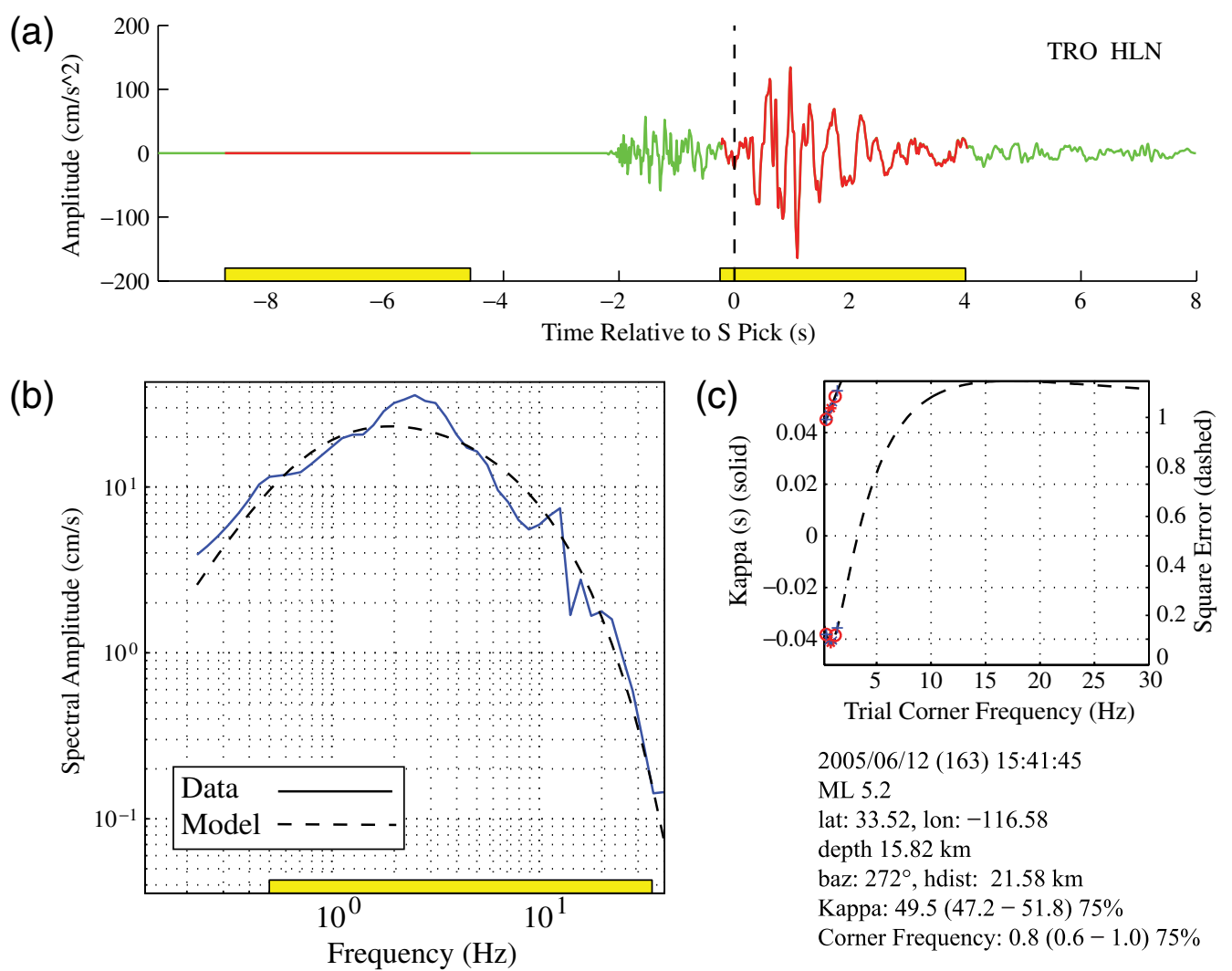

2005/06/12 (163) 15:41:45
ML 5.2
lat: 33.52 , lon: -116.58
depth $15.82 \mathrm{~km}$
baz: $272^{\circ}$, hdist: $21.58 \mathrm{~km}$
Kappa: $49.5(47.2-51.8) 75 \%$
Corner Frequency: $0.8(0.6-1.0) 75 \%$

Figure 4. Example from a portion of the summary figures that are automatically produced for each seismogram by the kappaAH software program. These data and results are from the 2005 magnitude 5.2 earthquake. These graphical views provide a quick quality check. (a) Time series from station TRO, horizontal component (HLN). The elongated rectangles indicate the time windows for the noise trace and the $S$-wave signal of interest. The $S$-wave arrival time is denoted by the dashed vertical line. (b) Spectrum of the $S$-wave signal (solid line) and the modeled fit (dashed line). (c) Dependence between kappa (solid line), the square error (dashed line), and the trial corner frequency. These data were chosen to illustrate cases of convergence in the minimum squared error as seen by the well developed minimum in the curve of RMS misfit as a function of the trial corner frequency in subfigure (c). The color version of this figure is available only in the electronic edition.

distance for SND and TRO, it is unchanged for KNW and decreases for PFO (see Fig. 5e,f). If the cause of these large differences was a near-source scattering effect, we would expect the displacement-kappa measurements from the two clusters (Hot Springs and Toro Peak) to have different distributions, but that is not observed. After ruling out magnitude, distance, and near-source effects, we conclude that the site effect is the most important contributor to the absolute value of displacement-kappa.

To judge the contributions to our measurements from deviations in earthquake sources and near-source scattering, we use the high density of small magnitude $\left(0.5<M_{\mathrm{L}}<1\right)$ earthquakes within the spatially small region of the Toro Peak cluster (see Fig. 1). From these data, we investigate the scatter in displacement-kappa measurements and assume that any deviations are attributed to deviations in earthquake focal mechanisms, peculiarities of the near-source path (e.g., through highly shattered material), and/or the heterogeneity of the host material near the source.

Displacement-kappa measurements at our four key stations (KNW, PFO, SND, and TRO) show a very small standard error of the mean $(<2 \mathrm{~ms})$, but the absolute values show a significant amount of scatter (>10 ms) (see Fig. 5). This suggests the mean value of the population is very well resolved (i.e., to within $2 \mathrm{~ms}$ ) and highlights the importance of using a substantial amount of data to establish baseline displacement-kappa properties. Because the site and path contributions to these measurements at a given station are nearly identical, we interpret the scatter in displacementkappa values to represent near-source influences.

We next compare the displacement-kappa results with the fixed-kappa results (see Table 4 and Fig. 6). We find minimal differences in the results from the data recorded at station KNW. For the PFO data, the differences are sometimes small (i.e., Hot Springs cluster data) and sometimes large (i.e., Toro Peak cluster data). At stations SND and TRO, the fixed-kappa results are generally $\sim 11 \mathrm{~ms}$ smaller than the displacement-kappa results. In all cases the standard error of the mean is smaller in the fixed-kappa results than in the displacement-kappa results, suggesting that fixing the stress drop stabilizes the method.

Overall, our results from small magnitude data suggest that site effects are the dominant influence of the absolute displacement-kappa values. Our results also suggest that 
(a)

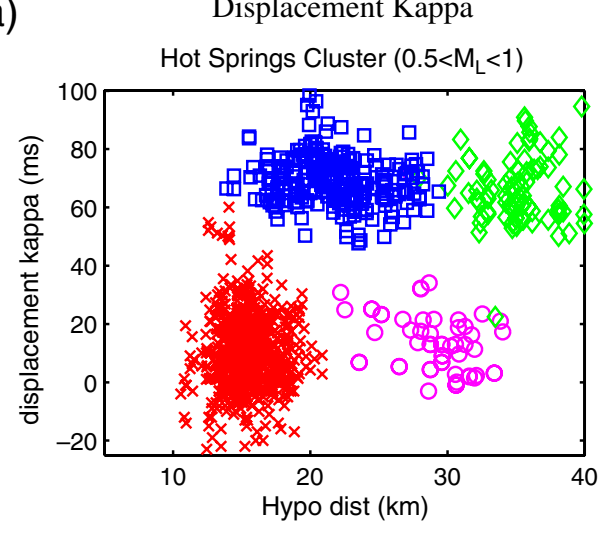

(c)

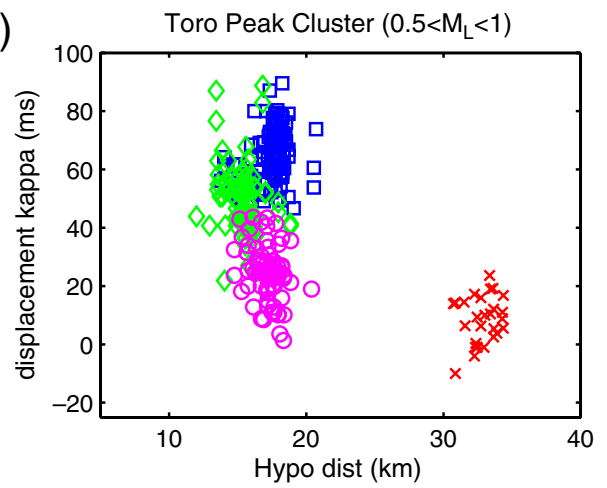

(e)

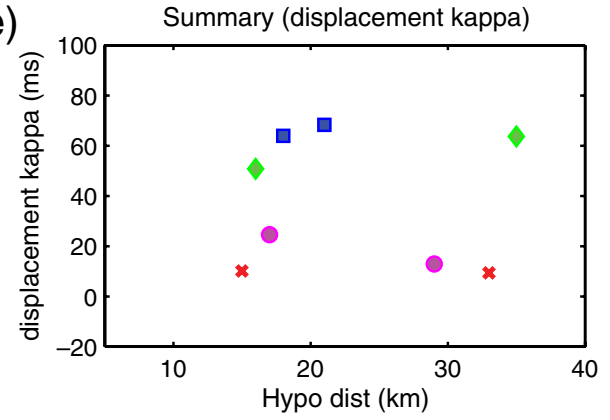

(b) Fixed Stressdrop Kappa

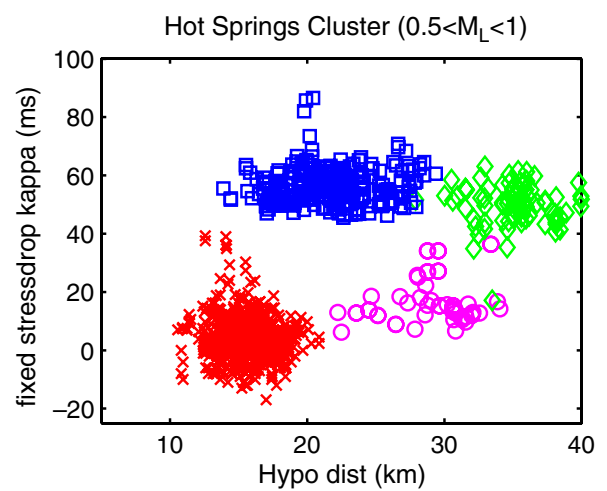

(d)

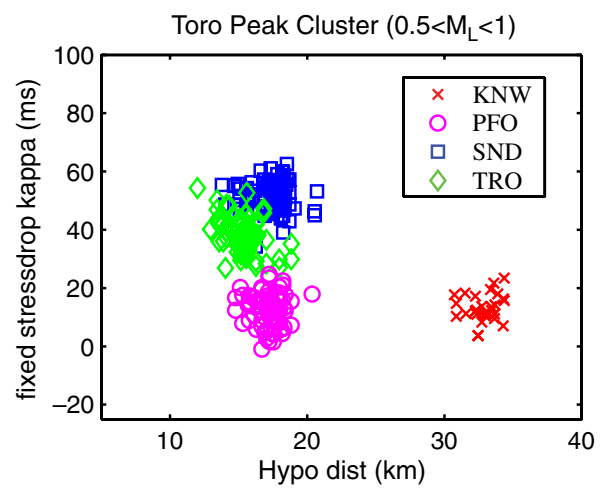

(f)

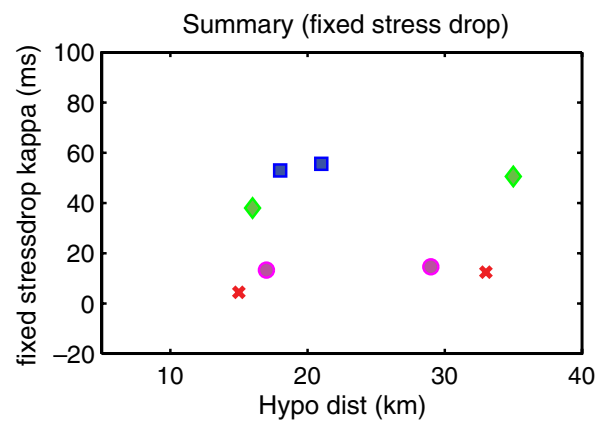

Figure 5. Influence of site conditions and hypocentral distances on kappa measurements using the data from ANZA stations KNW (x), PFO (o), SND (square) and TRO (diamond). (a) Displacement-kappa results using small magnitude $\left(0.5<M_{\mathrm{L}}<1\right.$ ) data from the Hot Springs cluster. (b) As in (a), but for fixed-kappa. (c, d) As in (a and b), but using the Toro Peak cluster data. (e) Summary of displacement-kappa results from both the Hot Springs and Toro Peak data. (f) Summary of fixed-kappa results from both the Hot Springs and Toro Peak data. Error bars for the summary figures are not shown, because they are smaller than the symbol sizes; see Table 4 for additional summary information. The tighter clustering observed when the stress drop is fixed suggests that variable corner frequency or numerical instability (kappa-corner trade-off) is responsible for most of the variability. The color version of this figure is available only in the electronic edition.

the scatter observed in displacement-kappa at a given station is strongly dependent on source properties or source-side scattering.

\section{AH-Kappa Results from Moderate}

Earthquakes $\left(M_{\mathrm{L}}>3.5\right)$

One difficulty we face is that AH-kappa measurements are best applied to earthquakes above magnitude 3.5 and the displacement-kappa measurements are best applied to earthquakes below magnitude 1.0. Elimination of earthquakes in the magnitude range 1.0-3.5 drastically reduces the number of earthquakes in a standard catalog. Fortunately, in our dataset we have a substantial number $(>1000)$ of earthquakes below magnitude 1.0 and 41 earthquakes above magnitude 3.5 . These 41 large/moderate earthquakes include 776 horizontal component seismograms, which were recorded at 13 ANZA network stations.

The AH-kappa measurements from these larger earthquakes (Fig. 6, Table 5) mimic the general results from our displacement-kappa measurement from the smaller magnitude data. For example, the AH-kappa measurements from 
the data recorded at stations KNW and PFO have relatively low AH-kappa values (i.e., 23-33 ms), whereas the data recorded at stations SND and TRO have relatively high AH-kappa values (i.e., $\sim 40-50 \mathrm{~ms}$ ). From these data we also find no strong evidence that AH-kappa values scale linearly with distance within our short $\sim 40 \mathrm{~km}$ source-station range, which is qualitatively consistent with the near-field results of Anderson (1991).

\section{Examination of Two Earthquakes over Magnitude}

Five in the ANZA Region

We next study the data from the two largest earthquakes in our catalog, the 31 October $2001 M_{\mathrm{L}} 5.1$ earthquake and the 12 June $2005 M_{\mathrm{L}} 5.2$ earthquake. Recordings of these earthquakes include velocity data (2001 and 2005) and acceleration data (2005 only). Almost all of the acceleration seismograms are on scale. Clipped waveforms and waveforms with a substantial DC offset after the event were not used. The computed AH-kappa, $M_{0}, f_{0}$, and stress drop values are given in Tables 6 and 7. We do not attempt to quantify standard errors, because our dataset contains only two earthquakes.

There are five stations (CRY, LVA2, MONP, RDM, and SOL) with sufficient data to compare AH-kappa values from the 2001 and 2005 earthquakes. Of these, only AH-kappa measurements from station MONP are similar to within a few milliseconds for both the north-south and east-west components. At the other stations, differences between AHkappa estimates from the 2001 and 2005 recordings are as high as $\sim 8-17 \mathrm{~ms}$ for at least one of the two horizontal components. Relatively large differences are also found when comparing the two horizontal component AH-kappa values for the data recorded at a given station for a given individual earthquake. These differences range up to $14 \mathrm{~ms}$, with even larger differences found from the data at station CRY ( $23 \mathrm{~ms}$, consistently logging lower AH-kappa values on the east-west component than those on the north-south component).

Our primary findings from the data recordings of these two large earthquakes show that, consistent with our displacement-kappa findings from small earthquakes, $\mathrm{AH}-$ kappa measurements at stations KNW and PFO are relatively low $(<15 \mathrm{~ms})$ compared with higher $(>30 \mathrm{~ms})$ measurements at station TRO and SND. In addition, the relatively large variability in AH-kappa results for the different component (i.e., north-south versus east-west) recordings of a given earthquake-site pair, and a similar mismatch between the results from the 2001 and 2005 earthquakes, indicates a single measurement from a single earthquake might not be representative of the median results from a large population of estimates.

Comparing Displacement-Kappa Measurements from

Small Earthquakes to AH-Kappa from Large

Earthquakes

In some regions, such as Yucca Mountain, Nevada, seismic hazard analyses (or strong-motion kappa estimates) infer what might occur in large earthquakes using data from small earthquakes because these are the only available data (Biasi and Anderson, 2007). However, is it reasonable to assume that we can estimate kappa parameters for use in strongmotion engineering based only on information from small earthquakes? To address this question, we use the ANZA network data to determine if displacement-kappa measurements derived from seismograms of small earthquakes $\left(M_{\mathrm{L}}<1\right)$ can reliably estimate AH-kappa values from larger earthquakes in the same region (i.e., the $41 M_{\mathrm{L}}>3.5$ earthquakes and two $M_{\mathrm{L}}>5$ earthquakes).

We compare kappa estimates at stations KNW, PFO, SND, and TRO for the three magnitude groups considered, where we limit the $M_{\mathrm{L}}<1$ earthquakes to the Toro Peak cluster data only (Fig. 6). At stations SND and TRO the small magnitude displacement-kappa measurements range

Table 4

Results* from Small Magnitude Events $\left(0.5<M_{L}<1\right)^{\dagger}$ from the Hot Springs (HS) Cluster of Seismicity, and Data from the Toro Peak (TP) Cluster of Seismicity

\begin{tabular}{ccccc}
\hline Cluster & Station & $\begin{array}{c}\text { Median Hypocentral } \\
\text { Distance }(\mathrm{km})\end{array}$ & $\begin{array}{c}\text { Median } \\
\text { Displacement-Kappa }(\mathrm{ms})^{\ddagger} \S\end{array}$ & $\begin{array}{c}\text { Median } \\
\text { Fixed-Kappa }(\mathrm{ms})^{\ddagger} \S\end{array}$ \\
\hline HS & KNW & 15 & $10.10 \pm 0.55(665)$ & $4.40 \pm 0.28(655)$ \\
TP & KNW & 33 & $9.40 \pm 1.56(27)$ & $12.40 \pm 0.93(27)$ \\
HS & PFO & 29 & $13.05 \pm 1.92(56)$ & $14.70 \pm 1.11(54)$ \\
TP & PFO & 17 & $24.60 \pm 1.17(70)$ & $13.25 \pm 0.67(70)$ \\
HS & SND & 21 & $68.30 \pm 0.58(249)$ & $55.60 \pm 0.40(247)$ \\
TP & SND & 18 & $63.90 \pm 0.94(101)$ & $52.90 \pm 0.48(101)$ \\
HS & TRO & 35 & $63.70 \pm 1.21(93)$ & $50.50 \pm 0.74(89)$ \\
TP & TRO & 16 & $50.75 \pm 1.26(84)$ & $38.00 \pm 0.63(84)$ \\
\hline
\end{tabular}

*All results are required to pass our quality tests that require the SNRpct to be greater than 0.75 .

tThese results are presented in Figure 5e,f.

Tabulated values are the median of the horizontal component data (i.e., both HHN and HHE).

${ }^{\S}$ The number of seismograms used in the computations are listed in parentheses, and the uncertainty values are derived from the standard error of the mean. 
(a)

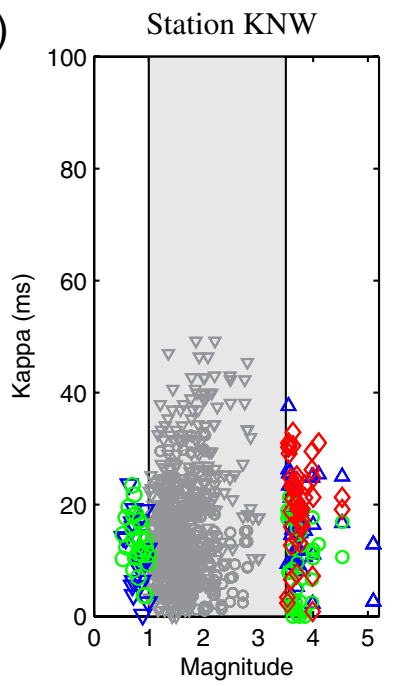

(b)

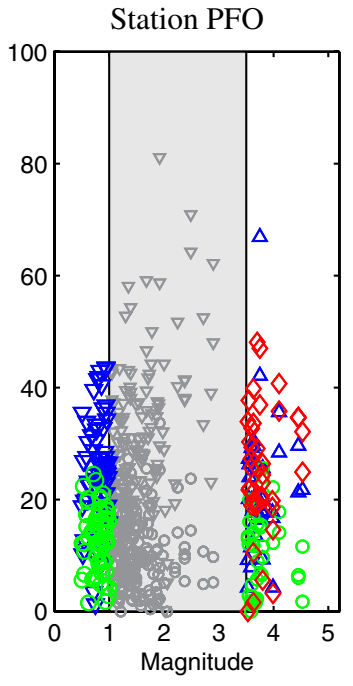

(c)

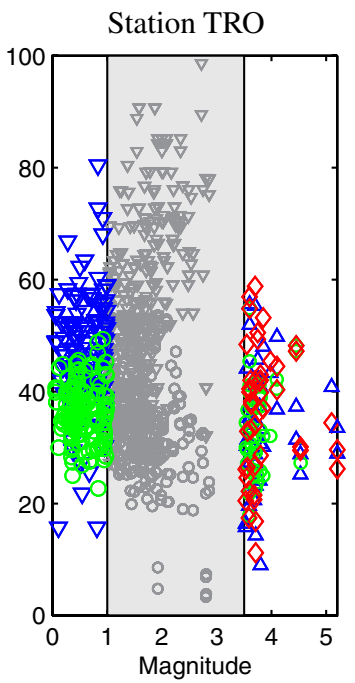

(d)

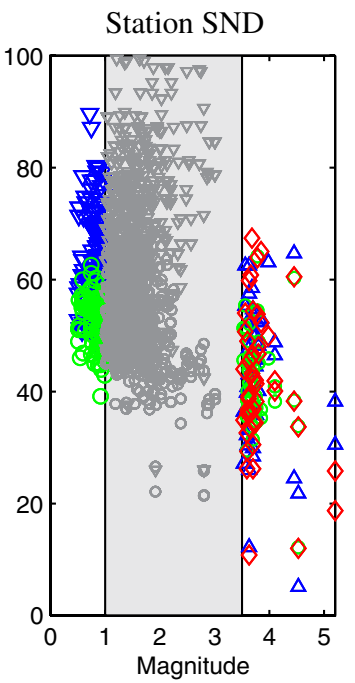

$\diamond$ AH-kappa

$\triangle$ Acc-slope kappa

$\nabla$ Disp-slope kappa

Fixed stress drop kappa

Magnitude range where kappa is somewhat ill defined.

Figure 6. Comparison of different kappa measurements from the HHE and HHN component recordings for small and large earthquakes in the Toro Peak cluster of seismicity. To augment these data, we also include results from the 41 large magnitude $(M>3.5)$ earthquakes that are within $40 \mathrm{~km}$ of the centroid of the ANZA network. For earthquakes in the magnitude range 1.0-3.5, the corner frequency falls in the range of frequencies used in the kappa measurements making the results not optimal, which is indicated by the large shaded rectangle encompassing this magnitude range. We use only horizontal component seismograms that have an $S$-wave phase pick and a SNRpct greater than 0.75. These data are from stations (a) KNW, (b) PFO, (c) TRO, and (d) SND. The color version of this figure is available only in the electronic edition.

from $\sim 50$ to $69 \mathrm{~ms}$, but for the larger earthquakes the AH-kappa measurements range from $\sim 36$ to $43 \mathrm{~ms}$. For stations KNW and PFO, however, displacement-kappa and AH-kappa measurements are similar-at $\sim 9-25 \mathrm{~ms}$ and $\sim 10-20 \mathrm{~ms}$, respectively. To summarize, we find that displacement-kappa measurements from small magnitude earthquakes predict the relative AH-kappa measurements from large magnitude earthquakes (see Tables 4, 5, 6, and 7), but small magnitude displacement-kappa measurements from the SND and TRO data can overestimate absolute values of AH-kappa for large magnitude earthquakes.

Agreement between Our Results and Previous Results that Use ANZA Data

We next compare our results with those from similar work that also study ANZA seismic network data. Hough et al. (1988) used the Anderson and Hough (1984) definition of kappa, designated as kappa(0). They assessed kappa(0) from $S$-wave data using 68 earthquakes (magnitude ranges from 1.7 to 4.4) that extend to hypocentral distances of $200 \mathrm{~km}$. Of these, only 20 earthquakes are within the footprint of the ANZA network. Because of the sparse data, Hough et al. (1988) had to rely on a linear regression technique to arrive at near-source kappa(0) estimates. They conclude that $\operatorname{kappa}(0)$ is primarily a near-station site effect, and changes in $\operatorname{kappa}(0)$ with distance are caused by attenuation along the path from source to receiver.
Similarities between the study of Hough et al. (1988) and this study include relatively low kappa(0) values at stations $\mathrm{KNW}(0.3 \pm 7 \mathrm{~ms})$ and PFO (3.5 $\pm 6 \mathrm{~ms})$ in comparison with those from the data at station SND $(18.1 \pm 13 \mathrm{~ms})$. The most striking difference between our results and the kappa(0) findings by Hough et al. (1988) is in kappa estimates derived from the data recorded at station TRO. Hough et al. (1988) report a kappa(0) value of $2.5 \mathrm{~ms}$, which is significantly less than our AH-kappa values of $\sim 34-37 \mathrm{~ms}$ (2001 $M_{\mathrm{L}} 5.1$ and $M_{\mathrm{L}} 3.5+$ events) and displacement-kappa values of $\sim 50-64 \mathrm{~ms}\left(0.5<M_{\mathrm{L}}<1\right.$ events). A possible reason for these $\sim 31-62 \mathrm{~ms}$ differences is, as mentioned earlier, that the corner frequency of the data from earthquakes in the $\sim 1-3.5$ magnitude range likely falls within the passband where kappa is being measured. This typically reduces the Anderson and Hough (1984) kappa values, which is consistent with the lower kappa(0) values found by Hough and coauthors. The problem with this explanation is that such differences are not found at all stations, indicating that these problems might contribute to the variations but cannot be solely responsible.

We favor an alternative hypothesis where the cause of the large differences between results stems from our TRO data being rich in earthquakes with short source-station paths (distances $<12 \mathrm{~km}$, primarily aftershocks of the 2001 and $2005 M_{\mathrm{L}} 5+$ main shocks), whereas the TRO data available to Hough et al. (1988) were restricted to much longer paths (distances $50-150 \mathrm{~km}$ ). Because TRO is the only station in the Hough et al. (1988) study that lacks near-field recordings, this 
Table 5

Results* from the 41 Large Earthquakes $\left(3.5<M_{L}<5.0\right)$ that Occurred within $40 \mathrm{~km}$ of the Network Centroid (see the map in Fig. 1)

\begin{tabular}{|c|c|c|c|c|c|c|}
\hline Station & Channel & $\kappa: \mathrm{AH}(\mathrm{ms})^{\dagger}$ & $\kappa:$ Sfix $(\mathrm{ms})^{\frac{j}{t}}$ & $\begin{array}{l}\text { Median } \\
\text { Magnitude }\end{array}$ & $\begin{array}{l}\text { Median Hypocentral } \\
\text { Distance }(\mathrm{km})\end{array}$ & $\begin{array}{c}\text { Number of Waveforms } \\
\text { Used }\end{array}$ \\
\hline $\mathrm{BZN}$ & HHE & 30.9 & 23.2 & 3.74 & 33.38 & 18 \\
\hline BZN & $\mathrm{HHN}$ & 40.5 & 22.3 & 3.70 & 30.49 & 19 \\
\hline CRY & HHE & 14.5 & 26.3 & 3.75 & 32.36 & 15 \\
\hline CRY & HHN & 52.3 & 35.0 & 3.73 & 39.63 & 18 \\
\hline FRD & HHE & 36.5 & 30.7 & 3.70 & 32.21 & 21 \\
\hline FRD & HHN & 20.3 & 25.7 & 3.71 & 33.99 & 20 \\
\hline KNW & HHE & 23.4 & 8.2 & 3.70 & 48.15 & 20 \\
\hline KNW & HHN & 22.6 & 7.8 & 3.70 & 48.15 & 20 \\
\hline LVA2 & HHE & 32.4 & 35.2 & 3.70 & 32.24 & 15 \\
\hline LVA2 & HHN & 50.5 & 41.3 & 3.70 & 30.72 & 20 \\
\hline MONP & HHE & 11.2 & 17.6 & 3.76 & 56.81 & 12 \\
\hline MONP & HHN & 28.6 & 17.6 & 3.76 & 56.81 & 12 \\
\hline PFO & HHE & 32.4 & 11.7 & 3.70 & 36.27 & 20 \\
\hline $\mathrm{PFO}$ & HHN & 26.2 & 7.7 & 3.70 & 36.27 & 20 \\
\hline RDM & HHE & 18.0 & 18.2 & 3.70 & 46.92 & 18 \\
\hline RDM & HHN & 25.7 & 17.9 & 3.70 & 50.20 & 19 \\
\hline SND & HHE & 50.6 & 42.2 & 3.70 & 41.27 & 16 \\
\hline SND & HHN & 44.3 & 43.2 & 3.71 & 42.41 & 16 \\
\hline SOL & HHE & 78.0 & 52.6 & 3.71 & 102.42 & 13 \\
\hline SOL & HHN & 65.3 & 46.9 & 3.71 & 102.42 & 13 \\
\hline TRO & EHE & 40.9 & 33.4 & 3.71 & 33.86 & 14 \\
\hline TRO & EHN & 40.3 & 33.1 & 3.71 & 34.87 & 15 \\
\hline WMC & HHE & 44.3 & 28.9 & 3.70 & 34.43 & 15 \\
\hline WMC & HHN & 42.2 & 26.5 & 3.71 & 35.33 & 19 \\
\hline YAQ & HHE & 53.2 & 29.3 & 3.75 & 30.02 & 7 \\
\hline YAQ & HHN & 47.7 & 35.0 & 3.75 & 30.02 & 9 \\
\hline
\end{tabular}

*We require that the corner frequency not be the maximum of the range tested, and we only report numbers for the data populations that exceed 5 seismograms.

†AH-Kappa

${ }^{\ddagger} \mathrm{AH}-\mathrm{Kappa}$ derived using a fixed stress drop of $4.7 \mathrm{MPa}$.

also explains why a mismatch is found only in the TRO data. We propose the extrapolation method required for the TRO data in the Hough study is the cause of the differing results. If this is correct, it indicates that the relationship between kappa and distance is not linear.

There are additional studies that examine the spectra of the data recorded by the ANZA network that focus on determining the parameter $T^{*}$, which, if $Q$ is assumed to be frequency independent, is proportional to kappa. In general, these studies site low $T^{*}$ values at stations $\mathrm{KNW}$ and PFO (Frankel and Wennerberg, 1989; Fletcher et al. 1990) and higher $T^{*}$ values at station SND (Frankel and Wennerberg, 1989), which is consistent with our displacement-kappa and AH-kappa results.

\section{Discussion}

Many, but not all, previous studies identify site-specific properties as primary contributors to the shape of the seismic spectra (e.g., Al-Shukri et al., 1995; Vernon et al., 1998; Prieto et al., 2007; Fernadez et al. 2010). Our results support these findings, but with an important caveat. Indeed, we expect that low kappa values at stations KNW and PFO likely result from relatively pristine near-surface conditions at these stations in comparison with those at station SND, which is directly within the San Jacinto fault zone, and station TRO, which is on an elongated ridge on top of a 2700-meter peak. However, while we conclude that site-specific properties are the most important contributor to the mean kappa value for each station, we also suggest that near-source properties control the scatter from that mean. This is motivated by the observation that at a given station, there is substantial variability in individual displacement-kappa measurements from the tight Toro Peak cluster data (see Fig. 5). The close proximity of these earthquakes makes their source-station paths similar, and we assume that site effects do not vary significantly with small changes in the angle of incidence near the station. Bolstering this hypothesis, the focal mechanisms of earthquakes in this source region are known to be highly heterogeneous (Jacobs et al., 2008; Bailey et al., 2010). Similar results concluding source-side properties likely influence spectra have been found from data in Guerrero, Mexico (Purvance and Anderson, 2003), Lotung, Taiwan (Tsai and Chen, 2000), and Canada (Atkinson, 1996).

Of all the data we consider, none suggest a strong systematic linear increase in kappa with source-station distance within the $\sim 40 \mathrm{~km}$ epicentral range of our data. 
Table 6

Results from the 31 October 2001 Magnitude 5.1 Earthquake*

\begin{tabular}{cccccccc}
\hline Station & Channel & $\begin{array}{c}\text { Epicentral } \\
\text { Distance }(\mathrm{km})\end{array}$ & $\begin{array}{c}\text { AH-Kappa } \\
\text { Value }(\mathrm{ms})\end{array}$ & $\begin{array}{c}M_{0} 1 \mathrm{e} 15 \\
(\mathrm{~N} \cdot \mathrm{m})\end{array}$ & $M_{\mathrm{w}}$ & $\begin{array}{c}\text { Stress Drop } \\
(\mathrm{MPa})\end{array}$ & $\begin{array}{c}\text { Corner } \\
\text { Frequency }(\mathrm{Hz})\end{array}$ \\
\hline TRO & EHE & 6.2 & - & - & - & - & - \\
TRO & EHN & 6.2 & 34.4 & $996^{\dagger}$ & $5.9^{\dagger}$ & 13 & 0.4 \\
FRD & HHE & 10.5 & - & - & - & - & - \\
FRD & HHN & 10.5 & - & - & - & - & - \\
PFO & HHE & 10.5 & - & - & - & - & - \\
PFO & HHN & 10.5 & - & - & - & - & - \\
SND & HHE & 11.6 & - & - & - & - & - \\
SND & HHN & 11.6 & - & - & - & - & - \\
BZN & HHE & 16.5 & - & - & - & - & - \\
BZN & HHN & 16.5 & - & - & - & - & - \\
WMC & HHE & 17.9 & - & - & - & - & - \\
WMC & HHN & 17.9 & - & - & - & - & - \\
LVA2 & HHE & 19.9 & 44 & 5 & 4.4 & $130^{\ddagger}$ & 5.2 \\
LVA2 & HHN & 19.9 & 47 & 5 & 4.4 & $135^{\ddagger}$ & 5.2 \\
CRY & HHE & 23.2 & 8.6 & 17 & 4.8 & 6 & 1.2 \\
CRY & HHN & 23.2 & 17.6 & 6 & 4.5 & 22 & 2.6 \\
KNW & HHE & 29.5 & - & - & - & - & - \\
KNW & HHN & 29.5 & - & - & - & - & - \\
RDM & HHE & 35.1 & 5.5 & 9 & 4.6 & 24 & 2.4 \\
RDM & HHN & 35.1 & 16.5 & 7 & 4.5 & $65^{\ddagger}$ & 3.6 \\
MONP & HHE & 70.1 & 21.5 & 12 & 4.7 & 6 & 1.4 \\
MONP & HHN & 70.1 & 17.8 & 9 & 4.6 & 5 & 1.4 \\
SOL & HHE & 103.3 & 55.7 & 50 & 5.1 & 27 & 1.4 \\
SOL & HHN & 103.3 & 59.6 & 53 & 5.1 & $61^{\ddagger}$ & 1.8 \\
\hline
\end{tabular}

*The table is sorted by epicentral distance; the symbol - indicates the results were not suitable for analysis, and of the 24 waveforms, 11 net reliable results (i.e., $46 \%$ ).

The overestimates of $M_{0}$ and $M_{\mathrm{w}}$ for the TRO data likely result because of the small separation between the source and recording station (Delouis et al., 2009).

Because stress drop scales with the cube of the corner frequency, uncertainties in these large stress drops are higher than the uncertainties in small stress drops.

This indicates that for many paths, the attenuation contribution to kappa can be very small, implying that the original model of kappa necessarily increasing linearly with distance does not apply for all data. In other recent studies, a nonlinear relationship between kappa and distance suggests that for some data, kappa increases with distance over short ranges (out to $\sim 40-70 \mathrm{~km}$ ) then remains relatively constant, or in some cases decreases (e.g., Fernandez et al., 2010). One interpretation of this nonlinear behavior is that longer sourcestation ray paths traverse different values of $Q$ in the lower crust (e.g., Hough and Anderson, 1988; Castro et al., 2009).

In the data recorded at stations SND and TRO, the absolute displacement-kappa measurements (50-68 ms) from small magnitude events $\left(0.5<M_{\mathrm{L}}<1.0\right)$ tend to overpredict the absolute AH-kappa values (34-43 ms) from large events $\left(M_{\mathrm{L}}>3.5\right)$ by $\sim 16-25 \mathrm{~ms}$. Distinctly different from this, we find comparable values in displacement-kappa and AH-kappa values in the data from stations PFO and KNW. If we only had access to the SND and TRO data, we might conclude that the smaller magnitude events systematically have lower stress drops than the larger magnitude events, but the data from KNW and PFO prove this is not the case. Instead, our interpretation of these findings is that for seismic recordings at relatively pristine sites, the high-frequency energy initiating from the earthquake source is preserved at the recording station. On the other hand, if a large portion of the travel path between the earthquake source and the recording station is highly brecciated fault zones, and more importantly, if the site conditions have minimal competence (e.g., a large amount of fault gouge, local scatterers, fracturing, shallow low velocity zones) as is likely the case for the data recorded at station SND, then the source-generated high frequencies are more attenuated. In general these differences result in higher kappa values at stations SND and TRO. We also suggest that site effects at stations SND and TRO might modulate the spectra or moment estimates of small and large earthquakes differently, and it is these variations that explain the differences between large- and small-earthquake kappa values at these stations. Recent studies have shown that nonlinear site effects could occur during moderate-size (e. g., $M$ 4-5) earthquakes if peak ground accelerations are on the order of a few tens of gals (Wu et al., 2010; Rubinstein, 2011).

Similar to previous studies, our results highlight the need for more than a single station to adequately predict ground motions within an extended region (Baltay et al., 
Table 7

Results from the 12 June $2005 M_{\mathrm{L}} 5.2$ Earthquake*

\begin{tabular}{|c|c|c|c|c|c|c|c|}
\hline Station & Channel & $\begin{array}{c}\text { Epicentral } \\
\text { Distance (km) }\end{array}$ & $\begin{array}{l}\text { AH-Kappa } \\
\text { Value (ms) }\end{array}$ & $M_{0} 1 \mathrm{e} 15(\mathrm{~N} \cdot \mathrm{m})$ & $M_{\mathrm{w}}$ & $\begin{array}{l}\text { Stress Drop } \\
\text { (MPa) }\end{array}$ & $\begin{array}{l}\text { Corner Frequency } \\
(\mathrm{Hz})\end{array}$ \\
\hline SND & HHE & 3.7 & - & - & - & - & - \\
\hline SND & HHN & 3.7 & - & - & - & - & - \\
\hline SND & HLE & 3.7 & 37.7 & 85 & 5.2 & 29 & 1.2 \\
\hline SND & HLN & 3.7 & 43 & 395 & 5.7 & 17 & 0.6 \\
\hline FRD & HHE & 4.1 & 8.7 & 13 & 4.7 & 2 & 1 \\
\hline FRD & HHN & 4.1 & - & - & - & - & - \\
\hline FRD & HLE & 4.1 & 11.2 & 21 & 4.8 & 2 & 0.8 \\
\hline FRD & HLN & 4.1 & 12.8 & 57 & 5.1 & 2 & 0.6 \\
\hline BZN & HHE & 8.7 & - & - & - & - & - \\
\hline BZN & HHN & 8.7 & - & - & - & - & - \\
\hline WMC & HHE & 9.8 & - & - & - & - & - \\
\hline WMC & HHN & 9.8 & - & - & - & - & - \\
\hline WMC & HLE & 9.8 & 24 & 175 & 5.4 & 34 & 1 \\
\hline WMC & HLN & 9.8 & 26.9 & 110 & 5.3 & 60 & 1.4 \\
\hline TRO & HHE & 14.6 & - & - & - & - & - \\
\hline TRO & HHN & 14.6 & - & - & - & - & - \\
\hline TRO & HLE & 14.6 & 58.1 & 843 & 5.8 & 85 & 0.8 \\
\hline TRO & HLN & 14.6 & 49.5 & 517 & 5.7 & 52 & 0.8 \\
\hline $\mathrm{PFO}$ & HHE & 14.7 & - & - & - & - & - \\
\hline PFO & HHN & 14.7 & - & - & - & - & - \\
\hline PFO & HLE & 14.7 & 10.5 & 60 & 5.1 & 49 & 1.6 \\
\hline $\mathrm{PFO}$ & HLN & 14.7 & 13.9 & 38 & 5.0 & 132 & 2.6 \\
\hline CRY & HHE & 14.9 & - & - & - & - & - \\
\hline CRY & HHN & 14.9 & - & - & - & - & - \\
\hline CRY & HLE & 14.9 & 11.1 & 52 & 5.1 & 10 & 1 \\
\hline CRY & HLN & 14.9 & 33.7 & 41 & 5.0 & 86 & 2.2 \\
\hline LVA2 & HHE & 19.7 & - & - & - & - & - \\
\hline LVA2 & HHN & 19.7 & - & - & - & - & - \\
\hline LVA2 & HLE & 19.7 & 27.3 & 1130 & 6.0 & 2 & 0.2 \\
\hline LVA2 & HLN & 19.7 & 34 & 315 & 5.6 & 4 & 0.4 \\
\hline KNW & HHE & 23.9 & - & - & - & - & - \\
\hline KNW & HHN & 23.9 & - & - & - & - & - \\
\hline KNW & HLE & 23.9 & $-9^{\dagger}$ & 68 & 5.2 & 3 & 0.6 \\
\hline KNW & HLN & 23.9 & $-9^{\dagger}$ & 20 & 4.8 & 7 & 1.2 \\
\hline RDM & HHE & 27 & - & - & - & - & - \\
\hline RDM & HHN & 27 & 4.6 & 24 & 4.8 & 13 & 1.4 \\
\hline RDM & HLE & 27 & 18.5 & 70 & 5.2 & 38 & 1.4 \\
\hline RDM & HLN & 27 & 16.7 & 50 & 5.1 & 40 & 1.6 \\
\hline YAQ & HHE & 45.4 & 30.7 & 56 & 5.1 & 19 & 1.2 \\
\hline YAQ & HHN & 45.4 & 28.3 & 15 & 4.7 & 24 & 2 \\
\hline YAQ & HLE & 45.4 & 29.8 & 119 & 5.3 & 12 & 0.8 \\
\hline YAQ & HLN & 45.4 & 26.3 & 22 & 4.8 & 18 & 1.6 \\
\hline MONP & $\mathrm{HHE}$ & 72.2 & 21 & 14 & 4.7 & 11 & 1.6 \\
\hline MONP & HHN & 72.2 & 17.1 & 24 & 4.9 & 5 & 1 \\
\hline SOL & HHE & 98.3 & 63.7 & 66 & 5.1 & 76 & 1.8 \\
\hline SOL & HHN & 98.3 & 59.3 & 68 & 5.2 & 78 & 1.8 \\
\hline
\end{tabular}

*The table is sorted by epicentral distance; the symbol — indicates the results were not suitable for analysis, and of the 46 waveforms, 28 net reliable results (i.e., $61 \%$ ).

†The negative AH-kappa values reflect a large amount of energy in the $\sim 10-12 \mathrm{~Hz}$.

2010). Within the context of seismic hazards, regions with lower kappa values are expected to produce larger ground motions than regions with higher kappa values. More quantitatively, kappa can be mapped to the Arias Intensity, a seismic hazard parameter that measures the potential destructiveness of an earthquake at a particular location (Stafford et al., 2009). The larger the Arias Intensity the higher the potential for destruction. Notably, kappa is not expected to scale linearly with Arias Intensity, such that a kappa increase from 0.01 to 0.1 corresponds to a decrease in the Arias Intensity by a factor of $\sim 8$ (Mena et al., 2010). A nonlinear dependence also exists between kappa and the peak ground acceleration (PGA), showing that an order of magnitude increase in kappa (0.01 to 0.1$)$ corresponds to a decrease in PGA by a factor of $\sim 3$ (Mena et al., 2010). Of course in practice other factors such as nonlinear site 
effects and/or basin-depth influences might alter these correlations (Field and Peterson, 2000; Wu et al., 2010; Rubinstein, 2011), but the primary nonlinear scaling relationship is expected to remain robust.

In this study, we explore differences in the fixed stressdrop and non-fixed stress-drop results to evaluate potential unresolved trade-offs between moment, corner frequency, and kappa. The theory that the range of stress drops is similar for earthquakes of all magnitudes is controversial. Some studies support the idea (Allmann and Shearer, 2009; Baltay et al., 2010), whereas other studies dispute it (Mayeda and Walter 1996; Mayeda et al., 2005). Specific to the southern California region, Shearer et al. (2006) studied over 60,000 earthquakes $\left(1.5<M_{\mathrm{L}}<3.1\right)$ and found no dependence between Brune-type stress drops and seismic moment, suggesting that the fixed stress drop model is a valid tool with which to explore kappa variations. The Shearer et al. (2006) work also indicates that along the SJFZ system the stress drops of small earthquakes $\left(M_{\mathrm{L}} 1.5-3.1\right)$ range from $\sim 1.0 \mathrm{MPa}$ to $2.5 \mathrm{MPa}$. This deviation in stress drop corresponds to $\pm 10 \mathrm{~Hz}$ variations in corner frequencies. The lower range in this variation could map into variable displacementkappa values because of corner-frequency effects introduced at the upper end of the measurement window. We therefore cannot rule out that low or variable stress drops contribute to the scatter in displacement-kappa values.

In a large portion of our small magnitude data the minimum value in the corner-frequency trade-off curve solution is poorly resolved. This, combined with the $\sim 10-13 \mathrm{~ms}$ difference between the fixed-kappa and the displacement-kappa results at stations TRO and SND, could indicate the corner frequencies are in or near the upper edge of the measurement window $\left(f_{0}<f_{\max }\right)$. However, fixing the stress drop has relatively little effect on results from the KNW and PFO station data, indicating the assumed $4.7 \mathrm{MPa}$ stress drop is reasonable for this region and argues against a systematic occurrence of low stress-drop events in our catalog. So, corner-frequency effects cannot be the only reason for the observed differences. Examining changes between our fixedkappa results and displacement-kappa results, we find smaller changes when displacement-kappa is low and larger changes when displacement-kappa is high. One way to interpret this is that site effects at SND and TRO modulate the spectra in a way to mask the true corner frequency, but site effects at KNW and PFO do not.

The two horizontal component recordings at station CRY exhibit systematic large differences in frequency content (Table 5), manifesting in 10-25 ms lower AH-kappa values for the east-west component data than the north-south component data. These differences are observed at multiple source-station distances and azimuths for both the $M 3.5+$ and $M 5+$ earthquakes and also observed on two different types of sensors (Tables 6,7). We therefore conclude there is a substantial nonisotropic site effect at station CRY.

In the now common empirical Green's function (EGF) method the source-time function of a relatively large earthquake is estimated by deconvolving the seismogram of a smaller earthquake that shares a similar path and focal mechanism (e.g., Dreger 1994). This approach assumes that the spectrum of the smaller earthquake approximates a point source containing primarily information about the path and site. If these assumptions are not correct, the resulting source-time function can be in error (e.g., Velasco et al., 1994; Kilb and Gomberg, 1999; Vallee, 2004; Iglesias and Singh, 2007). Our study suggests that finding an appropriate EGF could be difficult if the source zone of the larger earthquake is complex or highly heterogeneous. A possible solution to overcome this difficulty is to use an ensemble of EGFs to evaluate the sensitivity of the results to the selection of the EGF (e.g., Allmann and Shearer, 2007).

\section{Conclusions}

We estimate AH-kappa for $M_{\mathrm{L}}>3.5$ earthquakes and displacement-kappa for $M_{\mathrm{L}}<1$ earthquakes using highquality seismograms from 1180 local earthquakes that were recorded by the ANZA seismic network in southern California. The largest events we consider are two $M_{\mathrm{L}} \sim 5$ earthquakes. Our results show:

1. The mean kappa (displacement-kappa or AH-kappa) value of a relatively large population of closely located earthquakes is very well resolved ( $\pm 2 \mathrm{~ms})$, but a substantial amount of data is needed to establish these baseline values (i.e., individual measurements from only a few earthquakes may have considerable variability). We find that these mean values are strongly influenced by nearsite properties.

2. We expect that the scatter in displacement-kappa measurements from a given station is caused by source-side variability (e.g., differences in focal mechanisms and/or heterogeneity of the host material near the source). This was determined by restricting magnitude, site, path, and distance variability using small earthquakes in the geographically limited Hot Springs and Toro Peak clusters of seismicity.

3. The original model of kappa necessarily increasing linearly with distance does not strongly apply to the ANZA network data in this study, which extends out to epicentral distances of $\sim 40 \mathrm{~km}$.

4. The data from station CRY exhibits a strong nonisotropic site effect, such that the east-west component data has a prevalence of high-frequency energy (lower kappa) and the north-south component data is rich in low-frequency energy (higher kappa). Station CRY is the only ANZA station that consistently exhibits such a strong nonisotropic site behavior.

5. Displacement-kappa measurements from small magnitude earthquakes $\left(0.5<M_{\mathrm{L}}<1.0\right)$ can predict the relative AH-kappa measurements from larger magnitude earthquakes $\left(M_{\mathrm{L}}>3.5\right)$. Both populations show that kappa values at stations $\mathrm{KNW}$ and $\mathrm{PFO}$ are low and 
kappa values at stations TRO and SND are high. However, the absolute displacement-kappa values at stations TRO and SND appear to be biased upward compared to AH-kappa estimates from $M_{\mathrm{L}}>3.5$ events. Therefore, using absolute values of displacement-kappa derived from the small magnitude data recorded at stations SND and TRO will likely overestimate the true AH-kappa values of large earthquakes.

Overall, we conclude that near-site properties contribute to kappa values at a given station, but the scatter in these values results from a strong source-side contribution.

\section{Data and Resources}

Earthquake catalog data and seismograms were obtained by personal communication with members from the ANZA seismic network team (http://eqinfo.ucsd.edu/deployments/ anza/index.php, last accessed April 2010). Further information about the ANZA network operated by the Scripps Institution of Oceanography can be found at http:// eqinfo.ucsd.edu. The Antelope Real-Time System (ARTS) database extensions (http://www.brtt.com, last accessed April 2010) were used to process the data, and the software MATLAB (http://www.mathworks.com, last accessed April 2010) was used for computations, numerical analyses, and generating Figures 2-6. Figure 1 was made using the Generic Mapping Tools (www.soest.hawaii.edu/gmt; Wessel and Smith, 1998).

\section{Acknowledgments}

We thank those involved with the data collection, data analyses, and data archiving of the ANZA seismic network data. Thoughtful reviews from Eric Chael and two anonymous reviewers significantly improved this manuscript. We also thank Deborah Kane and Karen Felzer for early reviews of this manuscript and Rachael Abercrombie and Rob Mellors for helpful discussions. This project was completed under a subcontract from the University of Nevada at Reno (UNR-04-42) as part of the U.S. DOE/UCCSN Cooperative Agreement Number DE-FC28-98NV12081.

\section{References}

Abercrombie, R. E. (1995). Earthquake source scaling relationships from -1 to $5 M_{\mathrm{L}}$, using seismograms recorded at $2.5 \mathrm{~km}$ depth, J. Geophys. Res. 100, 24,015-24,036, doi 10.1029/95JB02397.

Aki, K., and P. G. Richards (2002). Quantitative Seismology, Second Ed., University Science Books, Sausalito, California.

Al-Shukri, H. J., G. L. Pavlis, and F. L. Vernon (1995). Site effect observations from broadband arrays, Bull. Seismol. Soc. Am. 85, 1758-1769.

Allman, B. P., and P. M. Shearer (2009). Global variations of stress drop for moderate to large earthquakes, J. Geophys. Res. 114, B01310, 22, doi 10.1029/2008JB005821.

Allmann, B. P., and P. M. Shearer (2007). Spatial and temporal stress drop variations in small earthquakes near Parkfield, California, J. Geophys. Res. 112, B04305, 17, doi 10.1029/2006JB004395.

Anderson, J. G. (1986). Implication of attenuation for studies of the earthquake source, in Earthquake Source Mechanics, Geophy. Monogr. Series 37, S. Das, J. Boatwright, and C.H. Scholz (Editors), American Geophysical Union, Washington, D.C., 311-318, doi 10.1029/ GM037p0311.
Anderson, J. G. (1991). A preliminary descriptive model for the distance dependence of the spectral decay parameter in southern California, Bull. Seismol. Soc. Am. 81, 2186-2193.

Anderson, J. G. (2007). Physical processes that control strong ground motion, in Earthquake Seismology, Treatise on Geophysics, Vol. 4, Hiroo Kanamori (Editor), Elsevier, Amsterdam, 513-565.

Anderson, J. G., and S. Hough (1984). A model for the shape of the fourier amplitude spectrum of acceleration at high frequencies, Bull. Seismol. Soc. Am. 74, 1969-1994.

Anderson, J. G., and J. R. Humphrey Jr (1991). A least-squares method for objective determination of earthquake source parameters, Seismol. Res. Lett. 62, 201-209.

Atkinson, G. M. (1996). The high-frequency shape of the source spectrum for earthquakes in eastern and western Canada, Bull. Seismol. Soc. Am. 86, 106-112.

Bailey, I. W., Y. Ben-Zion, T. W. Becker, and M. Holschneider (2010). Quantifying focal mechanism heterogeneity for fault zones in central and southern California, Geophys. J. Int. 183, 433-450 doi 10.1111/ j.1365-246X.2010.04745.x.

Baltay, A., G. Prieto, and G. C. Beroza (2010). Radiated seismic energy from coda measurements and no scaling in apparent stress with seismic moment, J. Geophys. Res. 115, B08314, 12, doi 10.1029/2009JB006736.

Beresnev, I. A. (2001). What we can and cannot learn about earthquake sources from the spectra of seismic waves, Bull. Seismol. Soc. Am. 91, 397-400, doi 10.1785/0120000115.

Berger, J., L. M. Baker, J. N. Brune, J. B. Fletcher, T. C. Hands, and F. L. Vernon (1984). The Anza array: A high-dynamic-range, broadband, digitally radiotelemetered seismic array, Bull. Seismol. Soc. Am. 74, 1469-1481.

Biasi, G. P., and J.G. Anderson (2007). Measurement of the parameter kappa, and reevaluation of kappa for small to moderate earthquakes at seismic stations in the vicinity of Yucca Mountain, Nevada, Final Technical Report TR-07-007, Nevada System of Higher Education (NSHE), University of Nevada, Las Vegas (UNLV), 232 pp, doi $10.2172 / 920643$.

Biasi, G. P., and K. D. Smith (2001). Site effects for seismic monitoring stations in the vicinity of Yucca Mountain, Nevada, MOL 20011204.0045, a report prepared for the US DOE/University and Community College System of Nevada (UCCSN) Cooperative Agreement.

Brune, J. N. (1970). Tectonic stress and the spectra of seismic shear waves from earthquakes, J. Geophys. Res. 75, 4997-5009, doi 10.1029/ JB075i026p04997.

Brune, J. N. (1971). Correction, J. Geophys. Res. 76, 5002.

Castro, R. R., C. I. Huerta, O. Romero, C. Jacques, A. Hurtado, and A. I. Fernandez (2009). Body-wave attenuation near the rupture of the 1887 Sonora, Mexico, earthquake $\left(M_{\mathrm{w}} 7.5\right)$, Geofís. Int. 48, 297-304.

Delouis, B., J. Charlety, and M. Vallée (2009). A method for rapid determination of moment magnitude $M_{\mathrm{w}}$ for moderate to large earthquakes from the near-field spectra of strong-motion records (MWSYNTH), Bull. Seismol. Soc. Am. 99, 1827-1840, doi 10.1785/0120080234.

Dreger, D. S. (1994). Empirical Green's function study of the January 17, 1994 Northridge, California earthquake, Geophys. Res. Lett. 21, 2633-2636, doi 10.1029/94GL02661.

Eshelby, J. D. (1957). The determination of the elastic field of an ellipsoidal inclusion and related problems, Proc R. Soc. London A 241, 376-396.

Fernández, A. I., R. R. Castro, and C. I. Huerta (2010). The spectral decay parameter kappa in northeastern Sonora, Mexico, Bull. Seismol. Soc. Am. 100, 196-206, doi 10.1785/0120090049.

Field, E. H., and M. D. Petersen (2000). A test of various site-effect parameterizations in probabilistic seismic hazard analyses of Southern California, Bull. Seismol. Soc. Am. 90, S222-S244, doi 10.1785/ 0120000502.

Fletcher, J. B., T. Fumal, H. P. Liu, and L. C. Carroll (1990). Near-surface velocities and attenuation at 2 boreholes near Anza, California, from logging data, Bull. Seismol. Soc. Am. 80, 807-831. 
Frankel, A., and L. Wennerberg (1989). Microearthquake spectra from the Anza, California, Seismic Network: Site response and source scaling, Bull. Seismol. Soc. Am. 79, 581-609.

Hanks, T. C. (1982). Fmax, Bull. Seismol. Soc. Am. 72, 1867-1879.

Hough, S. E., and J. G. Anderson (1988). High-frequency spectra observed at Anza, California: Implications for $Q$ structure, Bull. Seismol. Soc. Am. 78, 692-707.

Hough, S. E., J. G. Anderson, J. Brune, F. L. Vernon, J. Berger, J. Fletcher, L. Haar, T. Hanks, and L. Baker (1988). Attenuation near Anza, California, Bull. Seismol. Soc. Am. 78, 672-691.

Iglesias, A., and S. K. Singh (2007). Estimation of radiated energy using the EGF technique: What should be the upper limit of integration in the frequency domain? Bull. Seismol. Soc. Am. 97, 1346-1349, doi 10.1785/0120060204.

Jacobs, A. M., D. Kilb, and G. Kent (2008). 3-D interdisciplinary visualization: Tools for scientific analysis and communication, Seismol. Res. Lett. 79, 867-876, doi 10.1785/gssrl.79.6.867.

Kilb, D., and J. Gomberg (1999). The initial subevent of the 1994 Northridge, California, Earthquake: Is earthquake size predictable? J. Seismol. 3, 409-420, doi 10.1023/A:1009890329925.

Mayeda, K., and W. R. Walter (1996). Moment, energy, stress drop, and source spectra of western United States earthquakes from regional coda envelopes, J. Geophys. Res. 101, 11,195-11,208, doi 10.1029/ 96JB00112.

Mayeda, K., R. Gok, W. R. Walter, and A. Hofstetter (2005). Evidence for non-constant energy/moment scaling from coda-derived source spectra, Geophys. Res. Lett. 32, L10306, 4, doi 10.1029/2005GL022405.

Mena, B., P. M. Mai, K. B. Olsen, M. D. Purvance, and J. N. Brune (2010). Hybrid broadband ground-motion simulation using scattering Green's functions: Application to large-magnitude events, Bull. Seismol. Soc. Am. 100, 2143-2162, doi 10.1785/0120080318.

Press, F. (1964). Seismic wave attenuation in the crust, J. Geophys. Res. 69, 4417-4418, doi 10.1029/JZ069i020p04417.

Prieto, G. A., D. J. Thomson, F. L. Vernon, P. M. Shearer, and R. L. Parker (2007). Confidence intervals for earthquake source parameters, Geophys. J. Int. 168, 1227-1234, doi 10.1111/j.1365-246X.2006.03257.x.

Purvance, M. D., and J. G. Anderson (2003). A comprehensive study of the observed spectral decay in strong-motion accelerations recorded in Guerrero, Mexico, Bull. Seismol. Soc. Am. 93, 600-611, doi $10.1785 / 0120020065$.

Rubinstein, J. (2011). Nonlinear strong ground motion in medium magnitude earthquakes near Parkfield, California, Bull. Seism. Soc. Am. 101, 275-286, doi 10.1785/0120090396.

Sanders, C. O., and H. Kanamori (1984). A seismotectonic analysis of the Anza seismic gap, San Jacinto fault zone, southern California, J. Geophys. Res. 89, 5873-5890.

Shaw, B. (2009). Constant stress drop from small to great earthquakes in magnitude-area scaling, Bull. Seismol. Soc. Am. 99, 871-875, doi $10.1785 / 0120080006$.

Shearer, P. M., G. A. Prieto, and E. Hauksson (2006). Comprehensive analysis of earthquake source spectra in southern California, J. Geophys. Res. 111, B06303, doi 10.1029/2005JB003979.

Stafford, P. J., J. B. Berrill, and J. R. Pettinga (2009). New predictive equations for Arias intensity from crustal earthquakes in New Zealand, J. Seismol. 13, 31-52, doi 10.1007/s10950-008-9114-2.
Tikoff, B., B. van der Pluijm, J. Hibbard, G. R. Keller, D. Mogk, J. Selverstone, and D. Walker (2006). An integrated geologic framework for EarthScope's US array, Eos Trans. AGU 87, no. 23, 221, doi 10.1029/2006EO230001.

Tsai, C.-C. P., and K.-C. Chen (2000). A model for the high-cut process of strong-motion accelerations in terms of distance, magnitude, and site condition: An example from the SMART 1 array, Lotung, Taiwan, Bull. Seismol. Soc. Am. 90, 1535-1542, doi 10.1785/0120000010.

Vallée, M. (2004). Stabilizing the empirical green function analysis: Development of the projected Landweber method, Bull. Seismol. Soc. Am. 94, 394-409, doi 10.1785/0120030017.

Velasco, A. A., C. J. Ammon, and T. Lay (1994). Empirical green function deconvolution of broadband surface waves: Rupture directivity of the 1992 Landers, California $\left(M_{\mathrm{w}}=7.3\right)$, earthquake, Bull. Seismol. Soc. Am. 84, 735-750.

Vernon, F. L. (1989). Analysis of data recorded on the ANZA seismic network, Ph.D. Thesis University of California at San Diego.

Vernon, F. L., J. Fletcher, L. Carroll, A. Chave, and E. Sembera (1991). Coherence of seismic body waves from local events as measured by a small-aperture array, J. Geophys. Res. 96, 11,981-11,996, doi 10.1029/91JB00193.

Vernon, F. L., G. L. Pavlis, T. J. Owens, D. E. McNamara, and P. N. Anderson (1998). Near-surface scattering effects observed with a high-frequency phased array at Pinyon Flats, California, Bull. Seismol. Soc. Am. 88, 1548-1560.

Wu, C., Z. Peng, and Y. Ben-Zion (2010). Refined thresholds for nonlinear ground motion and temporal changes of site response associated with medium size earthquakes, Geophys. J. Int. 182, 1567-1576, doi 10.1111/j.1365-246X.2010.04704.X.

Wessel, P., and W. H. F. Smith (1998). New, improved version of generic mapping tools released, Eos Trans. AGU 79, 579, doi 10.1029/ 98EO00426.

Cecil H. and Ida M. Green Institute of

Geophysics and Planetary Physics (IGPP)

University of California, San Diego (USCD)

La Jolla, California

dkilb@epicenter.ucsd.edu

(D.K., F.L.V.)

University of Nevada Reno

Seismological Laboratory, MS-174

Reno, Nevada 89557

(G.B., J.A., J.B.)

School of Earth and Atmospheric Sciences

The Georgia Institute of Technology

ES\&T Building, Rm. 2256

311 Ferst Drive

Atlanta, Georgia, 30332-0340

(Z.P.)

Manuscript received 7 November 2010 